\title{
Socioeconomic Differences in the Long-Term Effects of Teacher Absence on Student Outcomes
}

\author{
Nicolai Topstad Borgen ${ }^{1,2}$, Simen Markussen ${ }^{3}$, and Oddbjørn Raaum ${ }^{3}$ \\ ${ }^{1}$ Department of Special Needs Education, University of Oslo, Oslo, Norway \\ ${ }^{2}$ Department of Sociology and Human Geography, University of Oslo, Oslo, Norway \\ ${ }^{3}$ Ragnar Frisch Centre for Economic Research, Oslo, Norway
}

July 2022

\section{Acknowledgments}

This work is supported by grants from the Norwegian Research Council (grant \#238050) and the European Research Council (grant \#818425). We thank Trond Petersen, Andreas Kotsadam, and Are Skeie Hermansen for comments on an earlier version of this manuscript. We also thank the participants at the Comparative Organizational Inequality Network (COIN) in Oslo 2020 for comments on an earlier version and participants in the 14th Conference of the European Sociological Association in Manchester, 2019. The data is made available for research by Statistics Norway.

\section{Corresponding author:}

Author: Nicolai Topstad Borgen

Affiliation: Department of Special Needs Education, Faculty of Educational Sciences, University of Oslo

Mailing address: P.O. Box 1140, Blindern, 0318 Oslo, Norway

Email address: n.t.borgen@ isp.uio.no 


\begin{abstract}
This paper examines the socioeconomic differences in the long-term effects of teacher absence. We use population-wide Norwegian register data to study the effects of certified teacher absence during lower secondary school (grades 8-10) on non-completion of upper secondary education by age 21 as well as academic achievement in $10^{\text {th }}$ grade. In a school fixed effects model, we find that an increase in teacher absence of 5 percentage points reduces students' examination grades by $2.3 \%$ of a standard deviation and increases the risk of dropout by 0.6 percentage points. However, these effects vary considerably by family background, with large effects for low-SES students driving the overall teacher absence effects. Overall, our findings indicate that reductions in instructional quality increase social inequality in long-term educational outcomes. This result highlights that studying heterogeneous impacts of contextual exposures is needed for understanding the role of schools in shaping inequality.
\end{abstract}

Keywords: Teacher absence, teacher effectiveness, dropout, academic achievement, socioeconomic gaps 


\section{Introduction}

The jury is still out on whether school heterogeneity reinforces or mitigates socioeconomic gradients in academic achievement and educational attainment (Downey and Condron 2016; Passaretta and Skopek 2021). While proponents of the reinforcement view point to unequal distribution of school resources along the lines of socioeconomic segregation in the US context (Adamson and Darling-Hammond 2012), compensating allocation of resources where schools with disadvantaged students have a lower student-teacher ratio is more prominent in other countries (Wößmann and West 2006). However, even if school resources are equal across socioeconomic groups, the effect of low school quality may differ across groups and contribute to educational inequality. This paper studies socioeconomic differences in the influence of teacher absence on students' long-term educational attainment as well as the final exam grades of compulsory schooling.

The effects of teacher qualifications on student learning, and its implications for social inequality, have been debated since the seminal Coleman report (Coleman et al. 1966) and have received an increasing focus of scientific studies across different disciplines (Reimer 2019; Morgan and Shackelford 2018). Several studies have demonstrated that teacher effectiveness is highly important for student learning (Hanushek and Rivkin 2006; Hanushek and Rivkin 2010; Kelly et al. 2018; Lee 2018), but there is less evidence on what makes a teacher good (or bad). As teaching quality has become a top priority on the education policy agenda around the world (Darling-Hammond 2017), the presence of stable teachers is a potentially important element, and some of the variance in student learning may stem from the absence of teachers (Miller et al. 2008).

Teacher absence is hypothesized to have sizeable effects on student achievement. For example, when the regular teacher is absent, the school is likely to substitute this teacher with a less qualified instructor or cancel class altogether because of the scarcity of substitute teachers 
(Miller et al. 2008; Bowers 2001). Additionally, teacher absence may result in disruption of classroom routines, lack of meaningful student-teacher relationships, lack of knowledge about students' specific skills, and failure to implement long-term instructional strategies (Miller et al. 2008). ${ }^{1}$ In line with this reasoning, recent studies have credibly identified adverse short-term effects of teacher absence on students' academic achievements (Miller et al. 2008; Clotfelter et al. 2009; Herrmann and Rockoff 2012).

However, we know little about whether teacher absence has heterogeneous effects and, in particular, whether these are important for students in the long run. The literature is scarce, consisting only of a handful of studies examining short-term average effects in grades 4-8 in the US. On the one hand, we know that poor academic achievements in primary school are a good predictor of long-term academic failure (Falch et al. 2014). On the other, we know from related research fields, such as the class size literature, that there may be substantial differences in effect sizes between countries (Wößmann and West 2006) and that the short-term effects on test scores may fade out (Chetty et al. 2011). Whether teacher absence effects are transmitted into long-term consequences is crucial; if they fade out, they are of little concern, as the damage created in the short-term gets repaired. However, there is ground for concern if the (differential) effects of teacher absence on student outcomes are long-lasting, resulting in a loss in student learning and increasing socioeconomic inequality.

We use population-wide Norwegian register data to study the effects of teacher absence during lower secondary school $\left(8-10^{\text {th }}\right.$ grade) on non-completion of upper secondary education five years later (by age 21). Further, we examine whether non-completion is explained by impairment of academic achievements (as measured by exam score at the end of grade 10). Teacher absence effects are identified using a school fixed effects model. Since students with

\footnotetext{
${ }^{1}$ Additionally, teacher absence may have a disruptive organizational influence on the school as a whole (Ronfeldt et al. 2013). Besides affecting the workplace moral (Rønning 2012), teacher absence consume administrative resources finding and paying substitute teachers (Clotfelter et al. 2009); resources that could rather be used on improving teaching and working conditions (Ronfeldt et al. 2013).
} 
low achievements are at high risk of school dropout, we also use quantile regression to examine whether the effects of teacher absence vary across the grade distribution. Further, we examine whether the consequences of teacher absence are less severe for students of high socioeconomic backgrounds than for other students. The mechanisms responsible for socioeconomic gradients in teacher absence effects are likely similar to those at play when instructional quality drops, such as school closure due to the COVID-19 pandemic (Engzell et al. 2021). As such, this paper concerns the interactions between instructional quality deficiencies and family background more generally.

\section{Teacher Absence and Socioeconomic Gradients}

\section{Effects of teacher absence}

The rate of teacher absence is about 5 to $6 \%$ in countries such as the United States (Herrmann and Rockoff 2012) and Norway (Rønning 2012), and about 3\% in the United Kingdom and Australia (Bradley et al. 2007). ${ }^{2}$ These rates amount to about 6-9 days per school year for an average teacher in these countries. In the US, absence rates are highest at schools that serve low-income students (Clotfelter et al. 2009).

Several policy reports and unpublished papers have indicated that teacher absence impairs student learning (see citations in Miller et al. 2008), except for Ehrenberg et al. (1991), which uses district-level data. However, these older studies have no explicit strategy to establish a causal link between teacher absence to student learning. Identifying a causal effect requires an identification strategy that accounts for three sources of bias, all of which are likely to

\footnotetext{
${ }^{2}$ Teacher absence rates in developing countries are considerably higher, with for example rates in the range of 20 to 44 percent begin reported in Kenya and India (Clotfelter et al. 2009). A randomized experiments in India demonstrated that reducing teacher absence in India 21 percentages points improved children's test scores by 0.17 standard deviation (Duflo et al. 2012).
} 
exaggerate the true effect. First, there is a potential negative correlation between teacher absence and teacher qualifications (Miller et al. 2008). Second, there is a possible reverse causality issue if the level of behavioral problems among the students affects teacher absence, and students with behavioral problems struggle academically (Clotfelter et al. 2009). Third, common shocks - such as an influenza outbreak - may increase teacher absence and directly affect students' learning.

Three studies that we know of have used a design that credibly accounts for these potential biases, all of which find that teacher absence harms short-term student outcomes (Miller et al. 2008; Clotfelter et al. 2009; Herrmann and Rockoff 2012). Miller et al. (2008) have access to student-teacher-year data and include teacher fixed effects in a value-added model to account for all time-invariant teacher characteristics. They find that teacher absence impairs students' achievements, suggesting that ten additional absence days reduce fourth-grade mathematics achievement by $3.2 \%$ of a standard deviation. ${ }^{3}$ Clotfelter et al. (2009), also using a value-added model with teacher fixed effects, find adverse effects of teacher absence in grades 4-5, but of a smaller magnitude than Miller et al. (2008). Having a teacher with ten additional absence days reduced math scores by about $1.7 \%$ of a standard deviation and reading by about 0.9\% of a standard deviation. Finally, like Miller et al. (2008) and Clotfelter et al. (2009), Herrmann and Rockoff (2012) find that teacher absences reduce the achievements of students, using a value-added teacher fixed effects model. They found that ten days of absence reduced students' math and English scores in grades $4-8$ by 1.2 and $0.6 \%$ of a standard deviation, respectively.

\footnotetext{
${ }^{3}$ Miller et al. (2008) also identify the local average treatment effect of (unplanned) teacher absence using the number of frigid days and number of days with a snow-pack as instrumental variables. The IV estimate is in the same direction, but 15 times larger than the OLS estimate.
} 


\section{Socioeconomic Gradients}

The academic development of a student is influenced by the quality of the teaching as well as her childhood environment. It is likely that a reduction in instructional quality - such as teacher absence - induces a compensatory response from parents in terms of shifts in household resources toward education (Becker and Tomes 1976; Todd and Wolpin 2003; Bonesrønning 2004; Houtenville and Conway 2008). Further, this compensatory response may vary with socioeconomic background.

Studies of birthweight effects (Torche and Echevarría 2011), sibship size effects (Tanskanen et al. 2016), and month of birth effects (Bernardi and Grätz 2015) have all shown that high-resource families compensate for any early disadvantage. One reason disadvantageous events such as teacher absence may be less harmful to children of high socioeconomic background is that parents may have the resources to buy services such as tutoring (Tanskanen et al. 2016) or simply instruct their kids more effectively. Another reason is that middle-class parents have higher educational expectations for their children (Roksa and Potter 2011) and may, to a greater extent, deliberatively cultivate their children for academic success (Lareau 2011). Parental involvement with school and children's academic development differs by socioeconomic background (Lareau 2011). Unlike middle-class parents, working-class parents give schools the primary responsibility for developing their children's cognitive skills. Consequently, teacher absence may be less likely to prompt compensatory responses among parents with low education. ${ }^{4}$

The effects of teacher absence may be stronger for disadvantaged children for other reasons than a weak compensatory response from parents. If school and family inputs are

\footnotetext{
${ }^{4}$ There is some evidence, however, suggesting a positive interaction effect of family and school resources. Kim (2001) finds that low-educated parents cut back on their childcare time use in response to an increase in per pupil school expenditure. Highly educated mothers, however, keep their childcare time fixed. When low-educated parents respond, teacher absence may be more harmful for children with highly educated parents, consistent with evidence of more adverse effects of parental divorce for these children (Bernardi and Radl 2014).
} 
substitutes, diminishing returns to inputs implies that school quality variation has less impact on students of high socioeconomic backgrounds. Disadvantaged children may suffer from less developmental stimulation from parents, and their human capital accumulation responds more strongly to changes in the learning environment in kindergarten and school. Such differential sensitivity to instructional quality by socioeconomic background is consistent with evidence that school and preschool programs are particularly important for disadvantaged children (Borman and Kimball 2005; Havnes and Mogstad 2015; Zachrisson et al. 2021). Additionally, differences by socioeconomic background in non-cognitive skills (Anger and Schnitzlein 2017) and the degree of behavioral problems (McLeod and Kaiser 2004) may contribute to disadvantaged students typically being more sensitive to disruptions in the learning environment. Studies have also suggested that a good student-teacher match serves as a protective force, especially for disadvantaged students and students at risk of academic failure (Crosnoe et al. 2004; Muller 2001). Teacher absence that disrupts such favorable relationships may be particularly harmful to these vulnerable children.

In line with these latter arguments, Clotfelter et al. (2009) find that short-term grades of disadvantaged students are most hurt by teacher absence. However, we do not know whether these short-term differential effects persist into adulthood.

\section{Data and Variables}

\section{Register Data and Analysis Sample}

We use population-wide Norwegian register data covering students born 1986-1999 who attend lower secondary schools (grades 8-10), excluding children of immigrants who arrive in Norway after school start (6 years old). Compulsory education in Norway starts at the age of six and lasts for ten years, with primary education in grades 1 to 7 and lower secondary 
education in grades 8 to 10 . Few students receive compulsory education in a private school (about 4\%), and all schools are publicly funded. There are three main types of schools in Norway: elementary schools (grade 1-7), lower secondary schools (grade 8-10), and combined elementary and lower secondary schools (grade 1-10). About $60 \%$ of the schools that provide lower secondary education are combined compulsory and lower secondary schools, and only $40 \%$ are lower secondary schools only. However, the lower secondary schools studied in this paper are larger and contain $74 \%$ of our study's birth cohorts.

\section{Teacher Absence Variable}

Ideally, we would like to track daily absences for all teachers and be able to link teachers to all students they have instructed throughout their school careers. The perfect teacher absence exposure for each individual student would reflect the time each student was planned to spend with their teacher. Unfortunately, however, such data are rarely available for research. Therefore, this paper's teacher absence measure is the average of the long-term teacher absence rate (lost days divided by the total number of days) certified by a doctor, aggregated to the school level during the three years when the student attended $8^{\text {th }}, 9^{\text {th }}$, and $10^{\text {th }}$ grade. This section discusses what we can learn from using this teacher absence measure.

Absence records stem from individual teacher records in the historical event database (FD-Trygd), which includes all sickness absence spells lasting 16 days or more. All such spells are covered by the social security system in Norway (from day 17), and a physician must certify them. The replacement rate is $100 \%$ during the absence, up to a ceiling amounting to $6 \mathrm{G}$ or around 60000 USD in annual earnings. The employer covers the first 16 days of absence, while the social security system covers the rest (up to one year). Absence information from administrative registers is more accurate than self-reported sickness absences (e.g., Kristensen et al. 2018; Short et al. 2009), partly because the reimbursement generates an incentive for 
employers to accurately report absences (Kristensen et al. 2018; Markussen et al. 2012).. However, our absence measure from the register data excludes certified sickness absence of fewer than 16 days and self-certified sick leave, which may be more detrimental than long-term absence (Herrmann and Rockoff 2012). Because our absence measure does not perfectly measure all sickness absences at school, our analyses probably provide a conservative estimate of the total effect of teacher absence. That said, for a few cohorts, we can observe all certified sickness absences. The correlation between long-term certified sickness absences and all certified sickness absences is 0.92 , suggesting only a small attenuation bias in our estimates.

The teacher-student matching information is not ideal as we rely on a unique school identifier that allows us to match students (from the National Education Database) and teachers (from the Register of Employers and Employees) to schools in Norway. We cannot match individual students and teachers within schools, but the teacher absence spells can be dated as part of a specific school year. For each school year, we observe the average long-term teacher absence rate (lost days divided by the total number of days) certified by a doctor. The treatment variable is the teacher absence at the student level (exposure), defined as the school average during the three school years when the student attended $8^{\text {th }}, 9^{\text {th }}$, and $10^{\text {th }}$ grade. Aggregating teacher absence at the school level results in an error-ridden measure of teacher absence. Nevertheless, in the following paragraphs, we argue that this aggregation leads to less precision but not the attenuation bias one might expect.

First, we aggregate teacher absence across different classes within the same grade. Unlike with classical measurement error, this type of measurement error is uncorrelated with the observed (aggregated) treatment variable, sometimes known as optimal prediction error (Hyslop and Imbens 2001). Importantly, this type of measurement error results in consistent point estimates, and the main drawback of aggregating teacher absence at the school cohort level is larger standard errors. 
Second, we aggregate teacher absence across different grades within the same school. Obviously, this aggregation results in an error-ridden measure of students' exposure to teacher absence. However, somewhat surprisingly, this aggregation is another example of optimal predictors that results in consistent but less precise estimates, as the measurement error is by definition independent of the observed value (Hyslop and Imbens 2001). To fix ideas, consider a model where the outcome $\left(Y_{i s c}\right)$ of student $i$ of cohort $c$ in school $s$ depends on teacher absence during each of the three school years $\left(T_{s c g}, g=8,9\right.$, and 10$)$ :

$$
Y_{i s c}=a+\sum_{g=8}^{10} \beta_{g} T_{s c g}+\varepsilon_{i s c}
$$

We do not observe teacher absence at the grade level but instead at the school level. For example, for cohort $c$ in their final year, we observe the school-level average $T S_{s c 10}=$ $\left(T_{s(c+2) 8}+T_{s(c+1) 9}+T_{s c 10}\right) / 3$. Assume that (i) only teacher absence in grade 10 matters $\left(\beta_{8}=\right.$ $\beta_{9}=0$ ), (ii) the number of teachers in each grade is the same, and (iii) that the absence rates of these three groups of teachers have the same variance $\left(\sigma_{g}^{2}\right)$. Then, two biases of equal magnitude operate in opposite directions and cancel out, as explained in the following paragraph and illustrated in the data simulations in Appendix C.

First, the measurement error results in a downward bias in the covariance between measured teacher absence $\left(T S_{s c 10}\right)$ and the outcome since only one-third of the variation in $T S_{s c 10}$ is relevant for the outcome. Simultaneously, taking the average of absence rates across $8^{\text {th }}, 9^{\text {th }}$, and $10^{\text {th }}$-grade teachers scales down the variance in the measured teacher absence variable by an equal amount (compared to the true variance among tenth-grade teachers), which cancels out any influence of the measurement error on the covariance. Thus, replacing the true tenth-grade teacher absence $\left(T_{s c 10}\right)$ with the error-ridden observed school-level teacher absence 
$\left(T S_{s c 10}\right)$ produce consistent estimates of the true effect of teacher absence in tenth grade, only less precisely estimated than if we could directly observe the absence of $10^{\text {th }}$-grade teachers.

This argument extends to a model where teacher absence during grades 8 and 9 also matters, and we measure the school average over all three grades: $T S_{s c}=\frac{T S_{s c 8}+T S_{S c 9}+T S_{S c 10}}{3}$. Thus, the interpretation of our estimated parameter is the effect on student outcomes by increasing teacher absence in all three years of lower secondary school. Appendix C uses a data simulation to show that replacing the true teacher absence with the error-ridden observed school-level teacher absence variable produces unbiased estimates of the teacher absence effect.

\section{Outcomes}

Long-term effects on educational attainment are measured by non-completion of upper secondary education at age 21 (labeled dropout). School dropout is definitely a high stake and associated with substantially reduced lifetime earnings. An illustration can be taken from the adult five-year average earnings distribution, where the differential between those who complete and those who do not are more than 12 percentiles (Online Appendix Table A6). More education is also likely to buy more than labor market success (Oreopoulos and Salvanes 2011), such as fewer health problems (e.g., Hoff et al. 2018). Following previous studies, we also investigate the effects of teacher absence on short-term academic performance, defined as the grade obtained in the final examination in lower secondary school $\left(10^{\text {th }}\right.$ grade $)$. Note that this exam is externally and anonymously graded. By extending the study beyond test (or exam) scores, we add to the literature by looking at long-term effects on an outcome important to individual lifetime welfare. 


\section{Socioeconomic Background and Control Variables}

Individual control variables are graduation cohort (dummies), gender, average of father's earnings while offspring student aged 11-15 (linear and quadratic term), average of mother's earnings at age 11-15 (linear and quadratic term), father's educational level (9 dummies), mother's educational level (9 dummies), immigrant background (dummies), age of immigration, whether father received social welfare at age 10-12, whether mother received social welfare at age 10-12, whether father received criminal charge at age 10-12, whether mother received criminal charge at age 10-12, birth order (linear and quadratic term), number of siblings (linear and quadratic term), father's age at birth (linear and quadratic term), and mothers' age of birth (linear and quadratic term).

At the school level, we control for the female share of teachers, the average age of teachers, the share of teachers with a master's degree, the share of teachers with teacher education, and the immigrant share among the teachers.

\section{Methods}

\section{School Fixed Effects Model}

Several school, teacher, and individual characteristics are likely correlated with teacher absence and students' outcomes. Unless properly accounted for, teacher absence effect estimates will be biased. We apply a school fixed effects model with controls for observable student and teacher characteristics:

$$
Y_{i s c}=\alpha+\delta T S_{s c}+\theta_{1} X_{i s c}+\theta_{2} M_{s c}+\eta_{s}+\gamma_{c}+\varepsilon_{i s c}
$$

, where $i, s$, and $c$ index individual, school, and cohort, respectively. $Y$ is the outcome variable, $T S$ is the average teacher absence rate measured at the school-cohort level during grades 8 to 
$10, X$ is individual control variables, and $M$ is teacher characteristics for each school cohort. The school fixed effect, $\eta_{s}$, captures all time-invariant differences between schools, such as stable teacher characteristics, student characteristics, and school resources. Within-school changes in student and teacher characteristics, such as an increase in students with behavioral problems, are adjusted for by means of control variables. Finally, the cohort fixed effect captures all mean differences between students across graduation years.

Our main parameter of interest is $\delta$, the regression coefficient for teacher absence on student performance. To give $\delta$ a causal interpretation, there must be no unobserved factors at the student or teacher level that correlate with teacher absence and influence student outcomes. The first concern is that there may be a negative correlation between teacher absence and teacher qualifications/school management effectiveness. For example, high-quality teachers may lead to less disturbance and a better learning environment for the students, resulting in less teacher absence. Having a high absence rate may also suggest that a teacher lacks skill or effort when teaching (Miller et al. 2008). Clotfelter et al. (2009) and Herrmann and Rockoff (2012) find that including teacher fixed effects shrinks the estimated effect of teacher absence. However, the evidence on quality-absence correlation is inconclusive; Miller et al. (2008) suggest that teachers with weak (unobserved) teaching skills are not more likely to be absent. In our school fixed effects model, we control for stable teacher and organizational characteristics at the school by means of school fixed effects and account for observable teacher characteristics that may change within schools (e.g., teachers' educational level).

Second, there may be a correlation between student characteristics and teacher absence. Studies have found that schools that serve disadvantaged children have persistently higher absence rates (Clotfelter et al. 2009). Because of the association between academic failure and behavioral problems (Evensen et al. 2016; Wertz et al. 2018), we may expect that students who struggle academically cause teachers to get sick leaves (reverse causality). This absence may, 
in turn, affect the performance of these vulnerable students (simultaneity bias). In our model, some of these factors are accounted for by including school fixed effects, and we account for family background by including variables such as parental education, parental earnings, parental social welfare, and parental criminal records. We also perform a series of robustness checks, which all indicate that the identifying assumptions are not violated (discussed in depth in the result section below).

\section{Quantile Treatment Effects}

The main analyses use ordinary least squares (OLS) to examine whether teacher absence affects long-term school dropout and short-term test scores (exams). To shed light on the role of short-term effects in explaining heterogeneous effects on school dropout, we also study how the short-term effects of teacher absence vary across the exam score distribution, using quantile regressions. Whether teacher absence translates into long-term impacts on dropout depends on whether teacher absence reduces the achievement level of high-achieving or low-achieving students. Suppose teacher absence depresses the academic achievements of high-achievers only. In that case, any impact on dropout is likely to be small simply because nearly all the affected students are completing upper secondary school anyway. In contrast, if teacher absence depresses low achievers' academic achievement, then any effect on dropout is potentially large because many of them are at risk.

To get a complete view of how teacher absence affects academic achievements, we identify unconditional quantile treatment effects (QTE) using the residualized quantile regression (RQR) model (Borgen et al. 2021b; Borgen et al. 2021a). ${ }^{5}$ Examination grades are

\footnotetext{
${ }^{5}$ An ongoing discussion on which quantile regression approach should be used to estimate QTEs is currently taking place (Wenz 2018; Killewald and Bearak 2014; Rios-Avila and Maroto 2020; Borgen et al. 2022). In our case, the coefficients are largely indistinguishable whether we use the RQR model or the generalized quantile regression (GQR) model of Powell (2016), both of which are developed to identify QTEs. Moreover, the overall pattern is similar when using the unconditional quantile regression model (Firpo et al. 2009), although the coefficients differ somewhat from the RQR and GQR models (Appendix Figure A6).
} 
calculated as the average test score of 2-3 examination grades, resulting in a discrete outcome distribution. We solve this problem by artificially smoothing the data using the jittering approach suggested by Machado and Silva (2005), which is similar in spirit to the oversmoothing approach Firpo et al. (2009) suggest in the RIF-OLS model. Specifically, we add uniform noise to jitter the outcome, using a uniform distribution over the interval $[-0.5,0.5]$. To test whether the results are sensitive to this artificial smoothing, we compare effects on smoothed examination grades with effects on grade point average, which should capture much of the same teacher absence effect. There is no need to smooth the grade point average variable since it consists of eleven subjects. Using the (unsmoothed) grade point average produces similar results as the smoothed examination grades (Appendix Figure A5).

\section{Results}

\section{Descriptive Statistics}

Our data's average certified teacher absence rate is about $4.7 \%$, which amounts to between eight and nine days of long-term absence per teacher during each school year (Table 1). This absence does not include short-term certified ( $<17$ days) or self-certified absences. Only $10 \%$ of the students are exposed to a teacher absence rate of less than $2.2 \%$, and only $10 \%$ are exposed to a rate of more than 7.5\% (Appendix Table A1, Appendix Figure A1 and A2). Thus, a difference of about ten absence days (i.e., 5.3 percentage points) separates the $90^{\text {th }}$ and $10^{\text {th }}$ percentiles. Some schools have persistently higher absence rates than others, resulting in a correlation between students' exposure to school-level teacher absence across grades of about $0.22\left(\rho_{8^{t h}}{ }^{t h}\right), 0.16\left(\rho_{8^{t h}}, 10^{t h}\right)$, and $0.24\left(\rho_{9^{t h}}, 10^{t h}\right)$ (Appendix Table A2). Nevertheless, these correlations suggest substantial variation in teacher absence across graduation cohorts within the same school. 
Table 1: Descriptive statistics

\begin{tabular}{|c|c|c|c|c|c|}
\hline & $\mathrm{N}$ & Mean & SD & Min & Max \\
\hline \multicolumn{6}{|l|}{ Outcome variables } \\
\hline Examination grades $\left(10^{\text {th }}\right.$ grade $)$ & 562246 & 0.030 & 0.995 & -3.652 & 2.246 \\
\hline Dropout (by age 21) & 368785 & 0.286 & 0.452 & 0.000 & 1.000 \\
\hline \multicolumn{6}{|l|}{ Treatment variable } \\
\hline Teacher absence rate $\left(8-10^{\text {th }}\right.$ grade $)$ & 555155 & 0.047 & 0.025 & 0.000 & 0.449 \\
\hline \multicolumn{6}{|l|}{ Individual controls } \\
\hline Graduation year & 587152 & 2008.671 & 3.998 & 2002.000 & 2015.000 \\
\hline Girl & 587152 & 0.486 & 0.500 & 0.000 & 1.000 \\
\hline Father's earnings & 582368 & 531688.639 & 323459.187 & 0.000 & 2722738.000 \\
\hline Mother's earnings & 587037 & 317706.540 & 198506.856 & 0.000 & 2722738.000 \\
\hline \multicolumn{6}{|l|}{ Father's education } \\
\hline No education & 582035 & 0.002 & 0.042 & 0.000 & 1.000 \\
\hline Primary education & 582035 & 0.003 & 0.054 & 0.000 & 1.000 \\
\hline Lower sec. education & 582035 & 0.198 & 0.399 & 0.000 & 1.000 \\
\hline Some upper sec. education & 582035 & 0.104 & 0.305 & 0.000 & 1.000 \\
\hline Upper sec. education & 582035 & 0.325 & 0.468 & 0.000 & 1.000 \\
\hline Post-sec. not higher education & 582035 & 0.053 & 0.223 & 0.000 & 1.000 \\
\hline Undergraduate education & 582035 & 0.205 & 0.403 & 0.000 & 1.000 \\
\hline Graduate education & 582035 & 0.091 & 0.288 & 0.000 & 1.000 \\
\hline Postgraduate education & 582035 & 0.012 & 0.108 & 0.000 & 1.000 \\
\hline Unknown & 582035 & 0.008 & 0.087 & 0.000 & 1.000 \\
\hline \multicolumn{6}{|l|}{ Mother's education } \\
\hline No education & 586983 & 0.003 & 0.051 & 0.000 & 1.000 \\
\hline Primary education & 586983 & 0.004 & 0.062 & 0.000 & 1.000 \\
\hline Lower sec. education & 586983 & 0.216 & 0.412 & 0.000 & 1.000 \\
\hline Some upper sec. education & 586983 & 0.114 & 0.317 & 0.000 & 1.000 \\
\hline Upper sec. education & 586983 & 0.260 & 0.439 & 0.000 & 1.000 \\
\hline Post-sec. not higher education & 586983 & 0.029 & 0.167 & 0.000 & 1.000 \\
\hline Undergraduate education & 586983 & 0.311 & 0.463 & 0.000 & 1.000 \\
\hline Graduate education & 586983 & 0.053 & 0.224 & 0.000 & 1.000 \\
\hline Postgraduate education & 586983 & 0.006 & 0.074 & 0.000 & 1.000 \\
\hline Unknown & 586983 & 0.005 & 0.073 & 0.000 & 1.000 \\
\hline \multicolumn{6}{|l|}{ Country of birth } \\
\hline NOR-born to NOR-born parents & 587147 & 0.882 & 0.322 & 0.000 & 1.000 \\
\hline FOR-born with two FOR-born parents & 587147 & 0.005 & 0.071 & 0.000 & 1.000 \\
\hline NOR-born to FOR-born parents & 587147 & 0.038 & 0.191 & 0.000 & 1.000 \\
\hline FOR-born with one NOR-born & 587147 & 0.001 & 0.038 & 0.000 & 1.000 \\
\hline NOR-born with one FOR-born parent & 587147 & 0.072 & 0.258 & 0.000 & 1.000 \\
\hline FOR-born to NOR-born parents & 587147 & 0.002 & 0.041 & 0.000 & 1.000 \\
\hline Year of immigration & 587152 & 0.028 & 0.367 & 0.000 & 6.000 \\
\hline Father social welfare & 586659 & 0.054 & 0.226 & 0.000 & 1.000 \\
\hline Father criminal charge & 586659 & 0.028 & 0.165 & 0.000 & 1.000 \\
\hline Mother criminal charge & 586659 & 0.007 & 0.084 & 0.000 & 1.000 \\
\hline Mother social welfare & 586659 & 0.062 & 0.241 & 0.000 & 1.000 \\
\hline Sibling order & 587150 & 1.887 & 0.988 & 0.000 & 17.000 \\
\hline Number of siblings & 587133 & 1.973 & 1.232 & 0.000 & 18.000 \\
\hline Father's age & 582394 & 31.402 & 5.837 & 10.000 & 75.000 \\
\hline Mother's age & 587043 & 28.544 & 5.016 & 13.000 & 54.000 \\
\hline \multicolumn{6}{|l|}{ Teacher controls } \\
\hline Teacher female & 562843 & 0.599 & 0.105 & 0.000 & 1.000 \\
\hline Teacher age & 562843 & 46.180 & 3.341 & 24.500 & 70.000 \\
\hline Teacher immigrant background & 562843 & 0.083 & 0.068 & 0.000 & 1.000 \\
\hline Teacher graduate education & 562843 & 0.116 & 0.087 & 0.000 & 1.000 \\
\hline Teacher education & 562843 & 0.724 & 0.132 & 0.000 & 1.000 \\
\hline
\end{tabular}




\section{Average Effects on Test Scores and Dropout}

The main results are presented in Table 2. We find that teacher absence during lower secondary school significantly reduces examination grades in $10^{\text {th }}$ grade. An increase in teacher absence rate of five percentage points - roughly equivalent to ten absence days or a comparison of a student at the $90^{\text {th }}$ percentile of the teacher absence distribution with a student at the $10^{\text {th }}$ percentile - reduces examination grades on average by $2.3 \%$ of a standard deviation (column 3). Teacher absence also significantly affects school dropout five years later. We find that a five percentage points increase in teacher absence increases dropout by 0.6 percentage points (column 6), corresponding to a $2.1 \%$ increase in the dropout rate (teacher absence effect divided by the overall dropout rate of $28.6 \%$ ). Table 2 also reveals that estimates of teacher absence effects are upward biased unless we control for time-invariant differences across schools by means of school fixed effects (compare columns 2 and 5 with 3 and 6).

Table 2: The estimated effects of teacher absence without any control variables (columns 1 and 4), with observed individual and teacher characteristics (columns 2 and 5), and with the full fixed effects model (columns 3 and 6).

\begin{tabular}{lcccccc} 
& $\begin{array}{c}(1) \\
\text { Examination } \\
\text { grades }\end{array}$ & $\begin{array}{c}(2) \\
\text { Examination } \\
\text { grades }\end{array}$ & $\begin{array}{c}(3) \\
\text { Examination } \\
\text { grades }\end{array}$ & $\begin{array}{c}(4) \\
\text { Dropout }\end{array}$ & $\begin{array}{c}(5) \\
\text { Dropout }\end{array}$ & $\begin{array}{c}\text { Dropout } \\
\text { Drates }\end{array}$ \\
\hline Teacher absence & $-0.8389^{* *}$ & $-0.6772^{* * *}$ & $-0.4612^{* *}$ & $0.1725^{*}$ & $0.1926^{* * *}$ & $0.1109^{* *}$ \\
& $(0.2708)$ & $(0.1470)$ & $(0.1430)$ & $(0.0874)$ & $(0.0408)$ & $(0.0361)$ \\
Control variables & & Yes & Yes & & Yes & Yes \\
School FE & & & Yes & & & Yes \\
Observations & 539036 & 534078 & 534078 & 349463 & 346551 & 346551 \\
\hline
\end{tabular}

Note: Standard errors clustered at schools in parentheses

${ }^{*} p<0.05,{ }^{* *} p<0.01,{ }^{* * *} p<0.001$

\section{Heterogeneous Effects of Teacher Absence}

We find that the effects of teacher absence vary considerably by students' achievement level and family background. Using quantile regressions, we find that the effect of teacher 
absence is more harmful to low-performing students (Figure 1). While teacher absence depresses examination grades across the entire outcome distribution, the effects are almost three times as large at the $10^{\text {th }}$ percentile compared to the $90^{\text {th }}$ percentile. ${ }^{6}$ Specifically, a five percentage point increase in teacher absence reduces examination grades by about $4.3 \%$ among the low-achievers $\left(10^{\text {th }}\right.$ percentile $)$, while only about $1.7 \%$ for the high-achievers $\left(90^{\text {th }}\right.$ percentile).

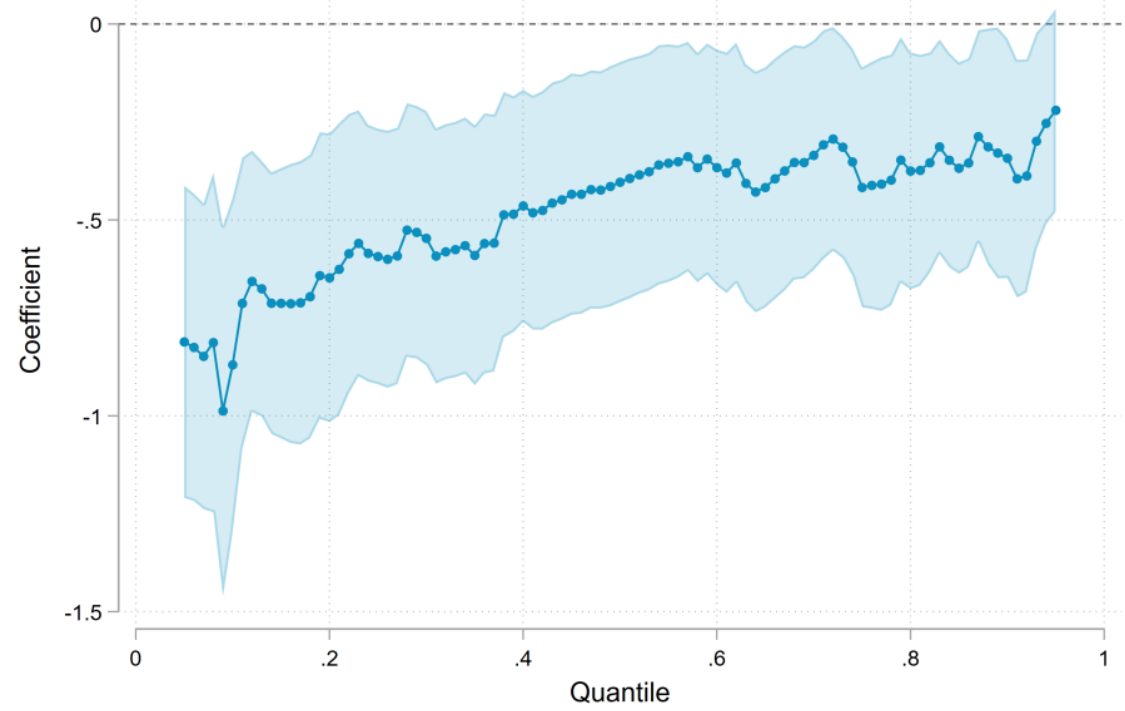

Figure 1: Effects of teacher absence on examination grades using quantile regressions.

Note: Appendix Table A4 includes point estimates and standard errors of the estimated effect as well of tests of significance of effects across quantiles. The shaded areas show 95\% confidence intervals based on 500 clusterbootstrapped standard errors.

In line with the heterogeneous effects across the exam score distribution, teacher absence is considerably more detrimental for students of low socioeconomic backgrounds (Table 3). In Panel A, teacher absence effects are different for students with high- or lowincome parents, defined as the parents' ${ }^{\prime}$ rank in the earnings distribution. Column (1) and (3) reports the estimated coefficients, whereas the regression coefficients are displayed as group-

\footnotetext{
${ }^{6}$ The heterogeneous effects across the outcome distribution is even more pronounced when looking at grade point average from upper secondary education, which includes all teacher-assessed grades and examination grades (Appendix Figure A5).
} 
specific effects in column (2) and (4). With students of low-rank parents as a reference, teacher absence effects are consistently lower and close to zero for advantaged students with parents in the upper half of the earnings distribution. Teacher absence effects by parental education point in the same direction (Panel B), but the estimates are less precise. While the interaction terms consistently show that effects are smaller for students with highly educated parents, only the higher education interaction is significant (and negative) for dropout. For example, for students of low parental education, an increase of teacher absence of 5 percentage points increases the likelihood of dropout by 1.1 percentage points $(.2219 * .05)$, compared to a 0.2 percentage point increase for high parental education students.

Table 3: Teacher absence effect by parental earnings and education.

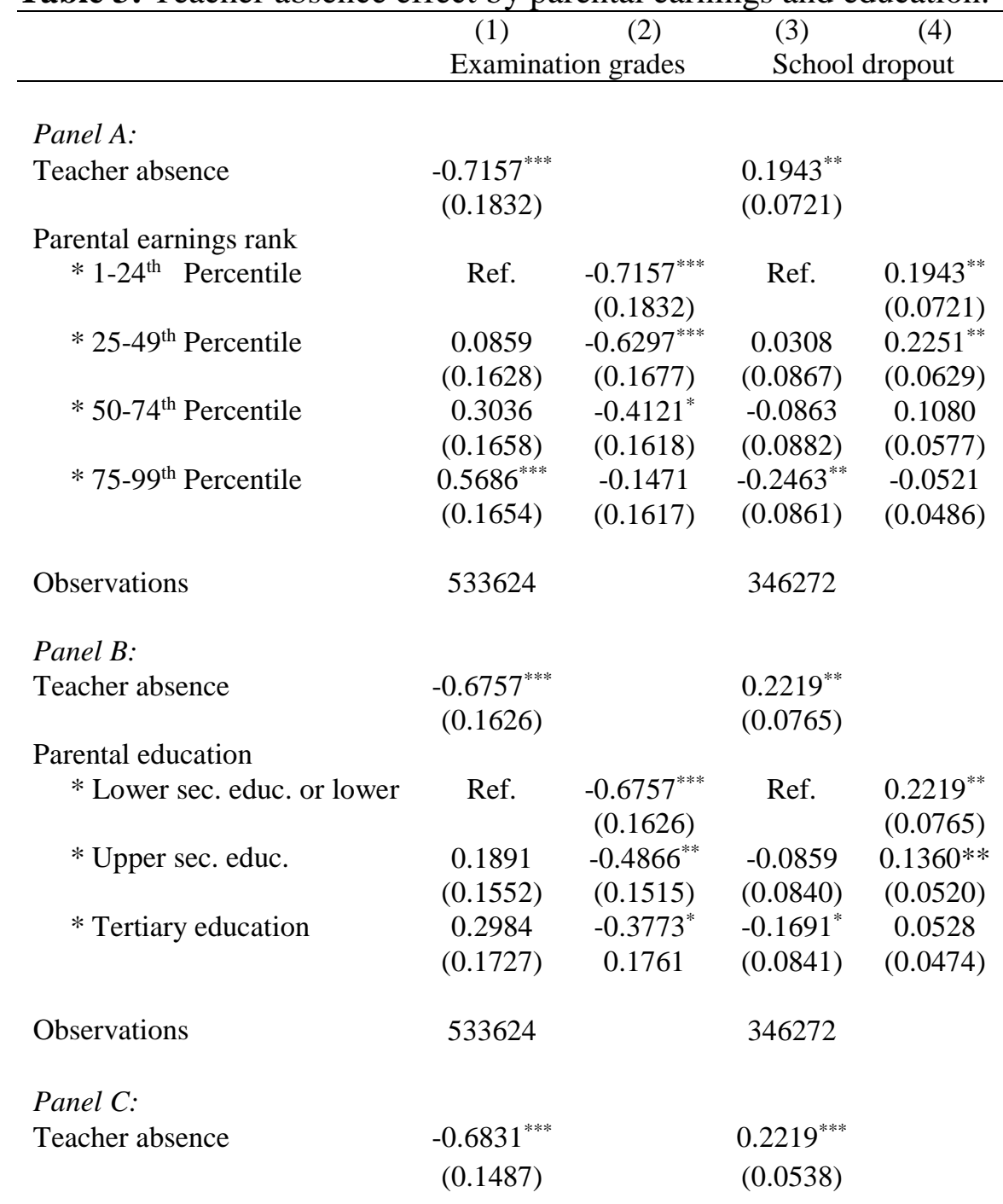




$\begin{array}{ccccc}\begin{array}{c}\text { Parental earnings rank } \\ * 1-49^{\text {th }} \text { Percentile }\end{array} & \text { Ref. } & -0.6831^{* * *} & \text { Ref. } & 0.2219^{* * *} \\ & & (0.1487) & & (0.0538) \\ * 50-99^{\text {th }} \text { Percentile } & 0.3732^{* *} & -0.3098^{*} & -0.1653^{*} & 0.0566 \\ & (0.1365) & (0.1543) & (0.0671) & (0.0608) \\ \text { Parental education } & & & & \\ * \text { No Tertiary education } & \text { Ref. } & -0.6831^{* * *} & \text { Ref. } & 0.2219^{* * *} \\ & & (0.1487) & & (0.0538) \\ * \text { Tertiary education } & 0.0502 & -0.6329^{* *} & -0.0498 & 0.1721^{*} \\ & (0.1455) & (0.2100) & (0.0667) & (0.0726)\end{array}$

Observations 533624

346272

Note: Standard errors clustered at school level in parentheses. All models with school fixed effects, individual controls, and teacher controls. Estimates in panels are from different models. Parental earnings rank is defined as the percentile rank of children based on parental earnings relative to children in the same graduation cohort, including those with zero earnings. Parental education refers to the highest achievement of the two parents. Estimates and standard errors in column (2) and (4) are based on (1) and (3), respectively, using lincom in Stata 16.0. In Panel $\mathrm{C}$ the column (2) and (4) estimates are the reference category for the other parental characteristic ${ }^{*} p<0.05,{ }^{* *} p<0.01,{ }^{* * *} p<0.001$

Contrasting the results by socioeconomic background, we find no clear differences in the effects of teacher absence by gender. The difference in teacher absence effect between boys and girls is small and not statistically significant, neither for examination grades nor dropout (Panel A, Table 4). Results are mixed for immigrant background. For examination grades, the effects of teacher absence are considerably larger (i.e., more negative) for children of immigrants than for natives (Panel B Table 4). An increase in teacher absence by five percentage points reduces examination grades by $7 \%$ of an SD (compared to $2.1 \%$ for natives), with $95 \%$ confidence intervals ranging from $10.6 \%$ of an SD to $3.5 \%$ (compared to $3.5 \%$ to $0.7 \%$ for natives). 
Table 4: Teacher absence effect by gender and immigrant background.

\begin{tabular}{|c|c|c|c|c|}
\hline & (1) & \multirow{2}{*}{$\begin{array}{l}(2) \\
\text { grades }\end{array}$} & (3) & \multirow{2}{*}{ (4) } \\
\hline & Exami & & School dropout & \\
\hline Teacher absence & $\begin{array}{l}-0.4128^{*} \\
(0.1739)\end{array}$ & & $\begin{array}{l}0.1583^{* *} \\
(0.0478)\end{array}$ & \\
\hline$*$ Boy & Ref. & $\begin{array}{l}-0.4128^{*} \\
(0.1739)\end{array}$ & Ref. & $\begin{array}{l}0.1583^{* *} \\
(0.0478)\end{array}$ \\
\hline * Girl & $\begin{array}{l}-0.1108 \\
(0.1410)\end{array}$ & $\begin{array}{c}-0.5235^{* * *} \\
(0.1434)\end{array}$ & $\begin{array}{l}-0.0933 \\
(0.0625)\end{array}$ & $\begin{array}{c}0.0651 \\
(0.0477)\end{array}$ \\
\hline Observations & 533624 & & 346272 & \\
\hline $\begin{array}{l}\text { Panel B: } \\
\text { Teacher absence }\end{array}$ & $\begin{array}{l}-0.4338^{* *} \\
(0.1441)\end{array}$ & & $\begin{array}{l}0.1198^{* *} \\
(0.0367)\end{array}$ & \\
\hline * Norwegian-born parent(s) & Ref. & $\begin{array}{c}-0.4338^{* *} \\
(0.1441)\end{array}$ & Ref. & $\begin{array}{l}0.1198^{* *} \\
(0.0367)\end{array}$ \\
\hline * Child of two immigrants & $\begin{array}{c}-0.9711^{* * *} \\
(0.3352)\end{array}$ & $\begin{array}{c}-1.4049^{* * *} \\
(0.3544)\end{array}$ & $\begin{array}{l}-0.2116 \\
(0.1761)\end{array}$ & $\begin{array}{l}-0.0918 \\
(0.1737)\end{array}$ \\
\hline Observations & 533624 & & 346272 & \\
\hline
\end{tabular}

Note: Standard errors clustered at school level in parentheses. All models with school fixed effects, individual controls, and teacher controls. Estimates in panels are from different models. Child of two immigrants are immigrants aged 5 or less at arrival and those born in Norway, all with two foreign-born parents. Estimates and standard errors in column (2) and (4) are based on (1) and (3), respectively, using lincom in Stata 16.0. ${ }^{*} p<0.05,{ }^{* *} p<0.01,{ }^{* * *} p<0.001$

Unfortunately, we do not have the power to identify differential effects of immigrant background on school dropout. Children of immigrants constitute 3.3\% of our sample at age 21. Furthermore, they are heterogeneous with respect to the country of origin and admission class, resulting in large standard errors (Appendix Figure A7 shows results by region of origin). Specifically, for an increase in teacher absence of five percentage points for children of immigrants, the $95 \%$ confidence intervals range from a massive reduction in dropout probability of 2.1 percentage points to a considerable increase of about 1.2 percentage points (compared to an increase between 0.2 and 0.9 for natives). 


\section{Robustness}

When concluding on cause-and-effect relationships, it is crucial to account for factors that may confound the estimates. Based on the school fixed effects model, we find that teacher absence impairs students' academic achievements and subsequently increases school dropout risk. Taking account of time-invariant school characteristics (i.e., school fixed effects) is seemingly important as the estimated effects of teacher absence without these fixed effects are considerably larger (Table 2). Still, a concern is that the within-school variation in teacher absence could be (partly) caused by variation in the share of students with behavioral and academic problems, even if we condition on time-variant student family background characteristics. Supplementary Online Appendix B investigates this concern empirically by exploiting data on students' entry test scores, students' behavioral problems (criminal charges and poor school behavior), school environment, and health visits. These supplementary analyses support our identification strategy.

\section{Discussion}

Teacher absence has been hypothesized to adversely affect student achievement (Miller et al. 2008). However, the literature is scarce, consisting of only a handful of studies credibly identifying short-term effects in grades 4-8 (Miller et al. 2008; Clotfelter et al. 2009; Herrmann and Rockoff 2012). In line with this evidence, we find robust evidence that teacher absence during grades $8-10$ impairs academic achievements in $10^{\text {th }}$ grade. We believe our study is the first to consider long-term student outcomes, and we find that teacher absence also increases the likelihood of school dropout by the age of 21 . Notably, the teacher absence effect varies greatly by students' socioeconomic background. The long-term impact on dropout is driven largely by a comparably sizeable adverse effect of teacher absence on academic achievements for low SES students. 
On average, we find that an increase of about five percentage points in teacher absence - roughly equivalent to comparing a student at the $90^{\text {th }}$ percentile of the teacher absence distribution with a student at the $10^{\text {th }}$ percentile - reduces examination grades by $2.3 \%$ of a standard deviation. This effect size is on par with the previous US results in grades 4-8, which suggests that ten days of absence (roughly equal to a difference of 5.3 percentage points) reduce mathematics scores by between $1.2 \%$ and $3.2 \%$, reading by $0.9 \%$, and English by $0.6 \%$ (Miller et al. 2008; Clotfelter et al. 2009; Herrmann and Rockoff 2012).

Teacher absence depresses the lower achievers' grades more than it does for the high achievers, suggesting stronger implications for their likelihood of later school dropout, since they are more likely to be at the margin for other reasons. In line with this, we find that the adverse effects of teacher absence on academic achievements in the lower end of the grade distribution translate into a sizeable effect on school dropout. An increase in teacher absence by five percentage points increases the likelihood of school dropout five years after completion of lower secondary school by 0.6 percentage points. This average effect size corresponds to a $2.1 \%$ increase in the dropout rate.

When teacher absence affects students' educational outcomes, teacher absence is also likely to influence social inequality (Downey and Condron 2016). Teacher absence can disproportionally harm disadvantaged students in two major ways. First, exposure to teacher absence can be higher in schools that serve disadvantaged students. Second, the effect can be larger for disadvantaged students. On exposure, we find that teacher absence in Norway is only weakly related to the students' socioeconomic and immigrant background (Appendix Table A7, Appendix Figure A4). For example, merely 0.5 percentage points of teacher absence separate students of the parents in the lower half of the earnings distribution from the parents in the top 1 percent. This equal exposure by socioeconomic background contrasts evidence from the US 
(Clotfelter et al. 2009), reflecting a modest degree of school and neighborhood segregation in Norway (Tammaru et al. 2015; Hermansen et al. 2020).

Despite negligible differences in teacher absence exposure by parental SES, our evidence shows that teacher absence contributes to social inequality in long-term educational attainment. Disadvantaged children bear most of the burden of teacher absence; for example, an increase in teacher absence of 5 percentage points increases the likelihood of dropout for students of low-income parents by about one percentage point. In contrast, the dropout rate is unaffected by teacher absence for students with high-income parents. This heterogeneous effect of teacher absence translates into an impact on the socioeconomic dropout gap. In a hypothetical world without teacher absence, the gap between high-income and low-income students may be over 4\% smaller (Appendix Table A9). This reduction is sizeable given that it is the effect of exposure over three school years only and that teacher absence is merely one of several contextual factors that may influence students' dropout rates.

This paper adds to a burgeoning literature demonstrating the importance of the school environment for social inequality even in relatively egalitarian school systems. For example, recent studies have shown that average estimates conceal that school effects may be stronger for some groups, such as children at risk of poor achievement (Cheesman et al. 2021). Moreover, it has been shown that students in the same schools may face different environments due to the within-school clustering of friendship networks (Engzell and Raabe 2022). This paper highlights that despite similar exposure to teacher absence, socioeconomic differences in the effects of teacher absence result in long-lasting social inequality in dropout rates. Thus, studying the heterogeneous impacts of contextual exposures is needed for understanding schools' role in shaping inequality.

Overall, the strong socioeconomic gradient in the effects of teacher absence could suggest that teacher absence induces a compensatory response from high-resource parents. That 
would be compatible with what is found in studies of compensatory advantage, such as birth weight effects (Torche and Echevarría 2011), sibship size effects (Tanskanen et al. 2016), and month of birth effects (Bernardi and Grätz 2015; Bernardi 2014). However, the socioeconomic gradients are compatible with other explanations too. To begin, if school and family inputs are substitutes, diminishing returns to total inputs implies that variation in teacher absence has less impact on students from high socioeconomic backgrounds compared to disadvantaged children. Further, the socioeconomic gradients in the effects of teacher absence can also be explained by disadvantaged students at risk of academic failure being more dependent on positive studentteacher relationships (Crosnoe et al. 2004) and being more sensitive to disruptions in the learning environment (Borman and Kimball 2005).

A question remains whether the impact on short-term academic achievement explains the long-term dropout effect. The importance of the path via previous academic performance relates directly to the causal effect of exam scores on future school dropout, which is intrinsically hard to identify empirically. Exam score at age 16 is a strong predictor of dropout at age 21 , but the association is largely driven by fixed individual factors explaining both. When we estimate the association between exam scores and dropout among same-sex twins (Appendix Table A8), the regression coefficient drops by about 50\%, and even this estimate should be interpreted as an upper bound on the causal effect of academic achievement at age 16 on dropout by age 21 . Thus, while we can convincingly address the confounding of teacher absence, credible evidence on the causal association between examination grades (the mediator) and the outcome school dropout is hard to establish.

The exact amount of mediation is also difficult to assess empirically for several other reasons (VanderWeele 2015). First, any measurement error in our measure of short-term academic achievements will attenuate the indirect effects of teacher absence. Second, teacher absence has larger effects on the academic achievements of low achievers, as shown by the 
quantile regressions, and the likelihood of dropout for low achievers is more influenced by their academic achievements than for high achievers (i.e., nonlinearity in both treatment-mediator association and mediator-outcome association) (Appendix Figure A8).

Because of these challenges, we can only provide a rough back-of-the-envelope calculation of how much of the long-term effects of teacher absence on dropout that operates via shorter-term academic achievements. ${ }^{7}$ Using the product method to map the effects of teacher absence on grades in different parts of the grade distribution (same-sex twin fixed effects) to the effects of grades on dropout across the grade distribution (quantile regression estimates), we find that the effect on academic achievements explains about one third (36\%) of the effect of teacher absence on future school dropout (Appendix Figure A9). ${ }^{8}$

\section{References}

Adamson, F. \& Darling-Hammond, L. (2012) 'Funding disparities and the inequitable distribution of teachers: Evaluating sources and solutions', education policy analysis archives 20: 37.

Anger, S. \& Schnitzlein, D. D. (2017) 'Cognitive skills, non-cognitive skills, and family background: evidence from sibling correlations', Journal of Population Economics 30: 591-620.

\footnotetext{
${ }^{7}$ We cannot use twin fixed effects to examine teacher absence effects because there is almost no variation in teacher absence within pairs of twins. Thus, controlling for academic achievements in a regression of dropout on teacher absence (i.e., the difference method to mediation) will introduce a collider bias (Elwert and Winship 2014; VanderWeele 2015).

${ }^{8}$ If we ignore non-linearity and simple calculate the product of the teacher absence effect on examination grades (Table 2) and the examination grades effect on dropout in a same-sex twin fixed effects model (Table A8), we find that academic achievements mediate about $30 \%$ of the association between teacher absence and school dropout $(-0.4612 *-0.0725=0.0334)$. Note that mediation methods will tend to exaggerate the achievement channel when the dropout equation's exam coefficient is upward biased. Suppose we use the exam coefficient from the school fixed effects model in Table A8 instead of the twin fixed effects model. In that case, $64 \%$ is mediated by achievement. Likewise, controlling for examination grades in a regression of dropout on teacher absence (i.e., the difference method) suggests that $58 \%$ of the variation is mediated by achievement, and the teacher absence effect is no longer significant at conventional levels (not shown).
} 
Becker, G. S. \& Tomes, N. (1976) 'Child endowments and the quantity and quality of children', Journal of political Economy 84: S143-S162.

Bernardi, F. (2014) 'Compensatory Advantage as a Mechanism of Educational Inequality:A Regression Discontinuity Based on Month of Birth', Sociology of Education 87: 74-88. Bernardi, F. \& Grätz, M. (2015) 'Making Up for an Unlucky Month of Birth in School: Causal Evidence on the Compensatory Advantage of Family Background in England', Sociological Science 2.

Bernardi, F. \& Radl, J. (2014) 'The long-term consequences of parental divorce for children's educational attainment', Demographic research 30: 1653-1680.

Bonesrønning, H. (2004) 'The determinants of parental effort in education production: do parents respond to changes in class size?', Economics of Education Review 23: 1-9.

Borgen, N. T., Haupt, A. \& Wiborg, Ø. (2021a) 'Flexible and fast estimation of quantile treatment effects: The rqr and rqrplot commands', SocArXiv 10.31235/osf.io/4vquh.

Borgen, N. T., Haupt, A. \& Wiborg, Ø. (2021b) 'A New Framework for Estimation of Unconditional Quantile Treatment Effects: The Residualized Quantile Regression (RQR) Model', SocArXiv doi:10.31235/osf.io/42gcb.

Borgen, N. T., Haupt, A. \& Wiborg, Ø. (2022) 'Quantile Regression Estimands and Models: Revisiting the Motherhood Wage Penalty Debate', SocArXiv doi:10.31235/osf.io/9avrp.

Borman, Geoffrey d. \& Kimball, Steven m. (2005) 'Teacher Quality and Educational Equality: Do Teachers with Higher Standards-Based Evaluation Ratings Close Student Achievement Gaps?', The Elementary School Journal 106: 3-20.

Bowers, T. (2001) 'Teacher Absenteeism and Ill Health Retirement: A review', Cambridge Journal of Education 31: 135-157.

Bradley, S., Green, C. \& Leeves, G. (2007) 'Worker absence and shirking: Evidence from matched teacher-school data', Labour economics 14: 319-334. 
Cheesman, R., Eilertsen, E. M., Ayorech, Z., Borgen, N. T., Andreassen, O. A., Larsson, H., Zachrisson, H. D., Torvik, F. A. \& Ystrom, E. (2021) 'How interactions between ADHD and schools affect educational achievement: a family-based genetically sensitive study'.

Chetty, R., Friedman, J. N., Hilger, N., Saez, E., Schanzenbach, D. W. \& Yagan, D. (2011) 'How does your kindergarten classroom affect your earnings? Evidence from Project STAR', The Quarterly Journal of Economics 126: 1593-1660.

Clotfelter, C. T., Ladd, H. F. \& Vigdor, J. L. (2009) 'Are teacher absences worth worrying about in the United States?', Education Finance Policy 4: 115-149.

Coleman, J. S., Campbell, E. Q., Hobson, C. J., Mcpartland, J., Mood, A. M., Weinfeld, F. D. \& York, R. (1966). Equality of educational opportunity. Washington, DC: US Government Printing Office.

Crosnoe, R., Johnson, M. K. \& Elder Jr, G. H. (2004) 'Intergenerational bonding in school: The behavioral and contextual correlates of student-teacher relationships', Sociology of education 77: 60-81.

Darling-Hammond, L. (2017) 'Teacher education around the world: What can we learn from international practice?', European Journal of Teacher Education 40: 291-309.

Downey, D. B. \& Condron, D. J. (2016) 'Fifty Years since the Coleman Report:Rethinking the Relationship between Schools and Inequality', Sociology of Education 89: 207-220.

Duflo, E., Hanna, R. \& Ryan, S. P. (2012) 'Incentives work: Getting teachers to come to school', American Economic Review 102: 1241-78.

Ehrenberg, R. G., Ehrenberg, R. A., Rees, D. I. \& Ehrenberg, E. L. (1991) 'School district leave policies, teacher absenteeism, and student achievement', Journal of Human Resources 26: 72-105.

Elwert, F. \& Winship, C. (2014) 'Endogenous Selection Bias: The Problem of Conditioning on a Collider Variable', Annual Review of Sociology 40: 31-53. 
Engzell, P., Frey, A. \& Verhagen, M. D. (2021) 'Learning loss due to school closures during the COVID-19 pandemic', Proceedings of the National Academy of Sciences 118: e2022376118.

Engzell, P. \& Raabe, I. (2022) 'Within-School Achievement Sorting in Comprehensive and Tracked Systems'.

Evensen, M., Lyngstad, T. H., Melkevik, O. \& Mykletun, A. (2016) 'The Role of Internalizing and Externalizing Problems in Adolescence for Adult Educational Attainment: Evidence from Sibling Comparisons using Data from the Young HUNT Study', European Sociological Review 32: 552-566.

Falch, T., Nyhus, O. H. \& Strøm, B. (2014) 'Performance of Young Adults: The Importance of Different Skills', CESifo Economic Studies 60: 435-462.

Firpo, S., Fortin, N. M. \& Lemieux, T. (2009) 'Unconditional quantile regressions', Econometrica 77: 953-973.

Hanushek, E. A. \& Rivkin, S. G. (2006) 'Teacher quality', Handbook of the Economics of Education 2: 1051-1078.

Hanushek, E. A. \& Rivkin, S. G. (2010) 'Generalizations about using value-added measures of teacher quality', American Economic Review 100: 267-71.

Havnes, T. \& Mogstad, M. (2015) 'Is universal child care leveling the playing field?', Journal of Public Economics 127: 100-114.

Hermansen, A. S., Borgen, N. T. \& Mastekaasa, A. (2020) 'Long-Term Trends in Adult SocioEconomic Resemblance between Former Schoolmates and Neighbouring Children', European Sociological Review 36: 366-380.

Herrmann, M. A. \& Rockoff, J. E. (2012) 'Worker absence and productivity: Evidence from teaching', Journal of Labor Economics 30: 749-782. 
Hoff, R., Corbett, K., Mehlum, I. S., Mohn, F. A., Kristensen, P., Hanvold, T. N. \& Gran, J. M. (2018) 'The impact of completing upper secondary education-a multi-state model for work, education and health in young men', BMC public health 18: 556.

Houtenville, A. J. \& Conway, K. S. (2008) 'Parental Effort, School Resources, and Student Achievement', Journal of Human Resources 43: 437-453.

Hyslop, D. R. \& Imbens, G. W. (2001) 'Bias from classical and other forms of measurement error', Journal of Business \& Economic Statistics 19: 475-481.

Kelly, S., Pogodzinski, B. \& Zhang, Y. (2018) 'Teaching Quality', in Schneider, B. (ed.) Handbook of the Sociology of Education in the 21st Century, Cham: Springer International Publishing, pp. 275-296

Killewald, A. \& Bearak, J. (2014) 'Is the Motherhood Penalty Larger for Low-Wage Women? A Comment on Quantile Regression', American Sociological Review 79: 350-357.

Kim, H.-K. (2001) 'Is there a crowding-out effect between school expenditure and mother's child care time?', Economics of Education Review 20: 71-80.

Kristensen, P., Corbett, K., Mohn, F. A., Hanvold, T. N. \& Mehlum, I. S. (2018) 'Information bias of social gradients in sickness absence: a comparison of self-report data in the Norwegian Mother and Child Cohort Study (MoBa) and data in national registries', BMC Public Health 18: 1275.

Lareau, A. (2011) Unequal childhoods: Class, race, and family life, Univ of California Press.

Lee, S. W. (2018) 'Pulling Back the Curtain: Revealing the Cumulative Importance of HighPerforming, Highly Qualified Teachers on Students' Educational Outcome', Educational Evaluation and Policy Analysis 40: 359-381.

Machado, J. a. F. \& Silva, J. S. (2005) 'Quantiles for counts', Journal of the American Statistical Association 100: 1226-1237. 
Markussen, S., Mykletun, A. \& Røed, K. (2012) 'The case for presenteeism-Evidence from Norway's sickness insurance program', Journal of Public Economics 96: 959-972.

Mcleod, J. D. \& Kaiser, K. (2004) 'Childhood emotional and behavioral problems and educational attainment', American sociological review 69: 636-658.

Miller, R. T., Murnane, R. J. \& Willett, J. B. (2008) 'Do teacher absences impact student achievement? Longitudinal evidence from one urban school district', Educational Evaluation and Policy Analysis 30: 181-200.

Morgan, S. L. \& Shackelford, D. T. (2018) 'School and Teacher Effects', in Schneider, B. (ed.) Handbook of the Sociology of Education in the 21st Century, Cham: Springer International Publishing, pp. 513-534

Muller, C. (2001) 'The role of caring in the teacher-student relationship for at-risk students', Sociological inquiry 71: 241-255.

Oreopoulos, P. \& Salvanes, K. G. (2011) 'Priceless: The Nonpecuniary Benefits of Schooling', The Journal of Economic Perspectives 25: 159-184.

Passaretta, G. \& Skopek, J. (2021) 'Does Schooling Decrease Socioeconomic Inequality in Early Achievement? A Differential Exposure Approach', American Sociological Review 86: $1017-1042$.

Powell, D. (2016) 'Quantile treatment effects in the presence of covariates', Review of Economics and Statistics 1-39.

Reimer, D. (2019) 'Teachers and teacher education: a call for a renewed sociological research agenda', International Studies in Sociology of Education 28: 90-109.

Rios-Avila, F. \& Maroto, M. L. (2020) 'Moving Beyond Linear Regression: Implementing and Interpreting Quantile Regression Models with Fixed Effects', SocArXiv doi:10.31235/osf.io/znj38. 
Roksa, J. \& Potter, D. (2011) 'Parenting and Academic Achievement:Intergenerational Transmission of Educational Advantage', Sociology of Education 84: 299-321.

Ronfeldt, M., Loeb, S. \& Wyckoff, J. (2013) 'How teacher turnover harms student achievement', American Educational Research Journal 50: 4-36.

Rønning, M. (2012). The effect of working conditions on teachers' sickness absence. Statistics Norway. Discussion Papers.

Short, M. E., Goetzel, R. Z., Pei, X., Tabrizi, M. J., Ozminkowski, R. J., Gibson, T. B., Dejoy, D. M. \& Wilson, M. G. (2009) 'How accurate are self-reports? Analysis of self-reported health care utilization and absence when compared with administrative data', Journal of occupational and environmental medicine 51: 786-796.

Tammaru, T., Van Ham, M., Marcińczak, S. \& Musterd, S. (2015) 'A multi-factor approach to understanding socio-economic segregation in European capital cities', Socio-economic segregation in European capital cities: Routledge, pp. 25-53

Tanskanen, A. O., Erola, J. \& Kallio, J. (2016) 'Parental resources, sibship size, and educational performance in 20 countries: evidence for the compensation model', Cross-Cultural Research 50: 452-477.

Todd, P. E. \& Wolpin, K. I. (2003) 'On the Specification and Estimation of the Production Function for Cognitive Achievement*', The Economic Journal 113: F3-F33.

Torche, F. \& Echevarría, G. (2011) 'The effect of birthweight on childhood cognitive development in a middle-income country', International Journal of Epidemiology 40: 1008-1018.

Torvik, F. A., Ystrom, E., Gustavson, K., Rosenström, T. H., Bramness, J. G., Gillespie, N., Aggen, S. H., Kendler, K. S. \& Reichborn-Kjennerud, T. (2018) 'Diagnostic and genetic overlap of three common mental disorders in structured interviews and health registries', Acta Psychiatrica Scandinavica 137: 54-64. 
Vanderweele, T. (2015) Explanation in causal inference: methods for mediation and interaction, Oxford University Press.

Wenz, S. E. (2018) 'What Quantile Regression Does and Doesn't Do: A Commentary on Petscher and Logan (2014)', Child development.

Wertz, J., Agnew-Blais, J., Caspi, A., Danese, A., Fisher, H. L., Goldman-Mellor, S., Moffitt, T. E. \& Arseneault, L. (2018) 'From Childhood Conduct Problems to Poor Functioning at Age 18 Years: Examining Explanations in a Longitudinal Cohort Study', Journal of the American Academy of Child \& Adolescent Psychiatry 57: 54-60. e4.

Wößmann, L. \& West, M. (2006) 'Class-size effects in school systems around the world: Evidence from between-grade variation in TIMSS', European Economic Review 50: 695-736.

Zachrisson, H. D., Dearing, E., Borgen, N. T., Sandsør, A. M. J. \& Karoly, L. A. (2021) 'Universal Early Childhood Education and Care for Toddlers and Achievement Outcomes in Middle Childhood', EdArXiv. November 30. doi:10.35542/osf.io/zrctw. 
Supplementary online appendix

\title{
Socioeconomic differences in the long-term effects of teacher absence on student outcomes
}

\author{
Nicolai Topstad Borgen ${ }^{1,2}$, Simen Markussen $^{3}$, and Oddbjørn Raaum ${ }^{3}$ \\ ${ }^{1}$ Department of Special Needs Education, University of Oslo, Oslo, Norway \\ ${ }^{2}$ Department of Sociology and Human Geography, University of Oslo, Oslo, Norway \\ ${ }^{3}$ Ragnar Frisch Centre for Economic Research, Oslo, Norway
}

\section{Content of the Supplementary Online Appendix:}

Appendix A: Supplementary tables and figures

Appendix B: Robustness checks

Appendix C: Data simulations 


\section{Online Appendix A: Supplementary tables and figures}

Table A1: Teacher absence by year

\begin{tabular}{lccccccccc}
\hline & Mean & SD & $5^{\text {th }}$ & $10^{\text {th }}$ & $25^{\text {th }}$ & $50^{\text {th }}$ & $75^{\text {th }}$ & $90^{\text {th }}$ & $95^{\text {th }}$ \\
\hline 2002 & 0.043 & 0.020 & 0.015 & 0.020 & 0.029 & 0.041 & 0.054 & 0.068 & 0.075 \\
2003 & 0.044 & 0.021 & 0.016 & 0.019 & 0.030 & 0.041 & 0.055 & 0.071 & 0.079 \\
2004 & 0.050 & 0.030 & 0.017 & 0.024 & 0.034 & 0.045 & 0.062 & 0.079 & 0.091 \\
2005 & 0.052 & 0.031 & 0.018 & 0.023 & 0.033 & 0.048 & 0.063 & 0.080 & 0.094 \\
2006 & 0.054 & 0.034 & 0.017 & 0.023 & 0.035 & 0.047 & 0.065 & 0.088 & 0.105 \\
2007 & 0.050 & 0.024 & 0.017 & 0.023 & 0.034 & 0.047 & 0.063 & 0.080 & 0.093 \\
2008 & 0.053 & 0.025 & 0.018 & 0.024 & 0.037 & 0.048 & 0.067 & 0.083 & 0.099 \\
2009 & 0.053 & 0.025 & 0.019 & 0.025 & 0.036 & 0.048 & 0.066 & 0.088 & 0.102 \\
2010 & 0.052 & 0.025 & 0.020 & 0.025 & 0.034 & 0.047 & 0.063 & 0.087 & 0.103 \\
2011 & 0.049 & 0.024 & 0.018 & 0.024 & 0.033 & 0.045 & 0.059 & 0.080 & 0.097 \\
2012 & 0.045 & 0.021 & 0.018 & 0.023 & 0.030 & 0.042 & 0.054 & 0.072 & 0.086 \\
2013 & 0.043 & 0.019 & 0.018 & 0.022 & 0.029 & 0.040 & 0.052 & 0.065 & 0.077 \\
2014 & 0.040 & 0.017 & 0.016 & 0.021 & 0.027 & 0.039 & 0.049 & 0.061 & 0.067 \\
2015 & 0.039 & 0.016 & 0.014 & 0.020 & 0.028 & 0.038 & 0.048 & 0.059 & 0.065 \\
Total & 0.048 & 0.025 & 0.017 & 0.022 & 0.032 & 0.044 & 0.059 & 0.075 & 0.091 \\
\hline
\end{tabular}

Table A2: Correlation between teacher absence rates in grades 8, 9, and 10 .

\begin{tabular}{llll}
\hline & $8^{\text {th }}$ grade & $9^{\text {th }}$ grade & $10^{\text {th }}$ grade \\
\hline $8^{\text {th }}$ grade & 1 & & \\
$9^{\text {th }}$ grade & $0.221^{* * *}$ & 1 & 1 \\
$10^{\text {th }}$ grade & $0.162^{* * *}$ & $0.236^{* * *}$ & 1 \\
${ }^{*} p<0.05,{ }^{* *} p<0.01,{ }^{* * *} p<0.001$ &
\end{tabular}

Table A3: Effects of teacher absence on grade point average from lower secondary school.

(1)

\begin{tabular}{lc} 
& Grade point average \\
\hline Teacher absence & $-0.2459^{* *}$ \\
& $(0.0950)$ \\
Control & Yes \\
Teacher & Yes \\
Observations & 540780
\end{tabular}

Note: Standard errors clustered at schools in parentheses. All models with school fixed effects, individual controls, and teacher controls.

${ }^{*} p<0.05,{ }^{* * *} p<0.01,{ }^{* * *} p<0.001$ 
Table A4: Effects of teacher absence on examination grades using RQR

\begin{tabular}{|c|c|c|c|c|c|}
\hline & $\begin{array}{c}(1) \\
10^{\text {th }} \text { percentile }\end{array}$ & $\begin{array}{c}(2) \\
25^{\text {th }} \text { percentile }\end{array}$ & $\begin{array}{c}(3) \\
50^{\text {th }} \text { percentile }\end{array}$ & $\begin{array}{c}\text { (4) } \\
75^{\text {th }} \text { percentile }\end{array}$ & $\begin{array}{c}(5) \\
90^{\text {th }} \text { percentile }\end{array}$ \\
\hline Teacher absence & $\begin{array}{c}-0.8697^{* * * *} \\
(0.2218)\end{array}$ & $\begin{array}{l}-0.5933^{* *} \\
(0.1851)\end{array}$ & $\begin{array}{l}-0.4037^{*} \\
(0.1959)\end{array}$ & $\begin{array}{l}-0.4170^{* *} \\
(0.1500)\end{array}$ & $\begin{array}{l}-0.3425^{*} \\
(0.1491)\end{array}$ \\
\hline Individual controls & Yes & Yes & Yes & Yes & Yes \\
\hline Teacher controls & Yes & Yes & Yes & Yes & Yes \\
\hline \multicolumn{6}{|l|}{$\begin{array}{l}\text { Difference in } \\
\text { coefficients }\end{array}$} \\
\hline vs. $10^{\text {th }}$ & & $\begin{array}{l}-0.2765^{*} \\
(0.1281)\end{array}$ & $\begin{array}{l}-0.4661 * * \\
(0.1711)\end{array}$ & $\begin{array}{l}-0.4527 * \\
(0.2033)\end{array}$ & $\begin{array}{l}-0.5272 * \\
(0.2230)\end{array}$ \\
\hline vs. $25^{\text {th }}$ & $\begin{array}{c}0.2765^{*} \\
(0.1281)\end{array}$ & & $\begin{array}{r}-0.1896 \\
(0.1069)\end{array}$ & $\begin{array}{r}-0.1763 \\
(0.1488)\end{array}$ & $\begin{array}{r}-0.2508 \\
(0.1766)\end{array}$ \\
\hline vs. $50^{\text {th }}$ & $\begin{array}{l}0.4661 * * \\
(0.1711)\end{array}$ & $\begin{array}{r}0.1896 \\
(0.1069)\end{array}$ & & $\begin{array}{r}0.0133 \\
(0.1054)\end{array}$ & $\begin{array}{r}-0.0612 \\
(0.1515)\end{array}$ \\
\hline vs. $75^{\text {th }}$ & $\begin{array}{c}0.4527^{*} \\
(0.2033)\end{array}$ & $\begin{array}{r}0.1763 \\
(0.1488)\end{array}$ & $\begin{array}{r}-0.0133 \\
(0.1054)\end{array}$ & & $\begin{array}{r}-0.0745 \\
(0.1215)\end{array}$ \\
\hline vs. $90^{\text {th }}$ & $\begin{array}{c}0.5272^{*} \\
(0.2230)\end{array}$ & $\begin{array}{r}0.2508 \\
(0.1766)\end{array}$ & $\begin{array}{r}0.0612 \\
(0.1515)\end{array}$ & $\begin{array}{r}0.0745 \\
(0.1215)\end{array}$ & \\
\hline Observations & 534078 & 534078 & 534078 & 534078 & 534078 \\
\hline
\end{tabular}

Note: Standard errors clustered at schools in parentheses. All models with school fixed effects, individual controls, and teacher controls. The difference in coefficients show difference between coefficients at different quantiles, along with the standard error of the difference.

${ }^{*} p<0.05,{ }^{* *} p<0.01,{ }^{* * *} p<0.001$

Table A5: Including teacher absence measured during grades 8, 9, and 10 .

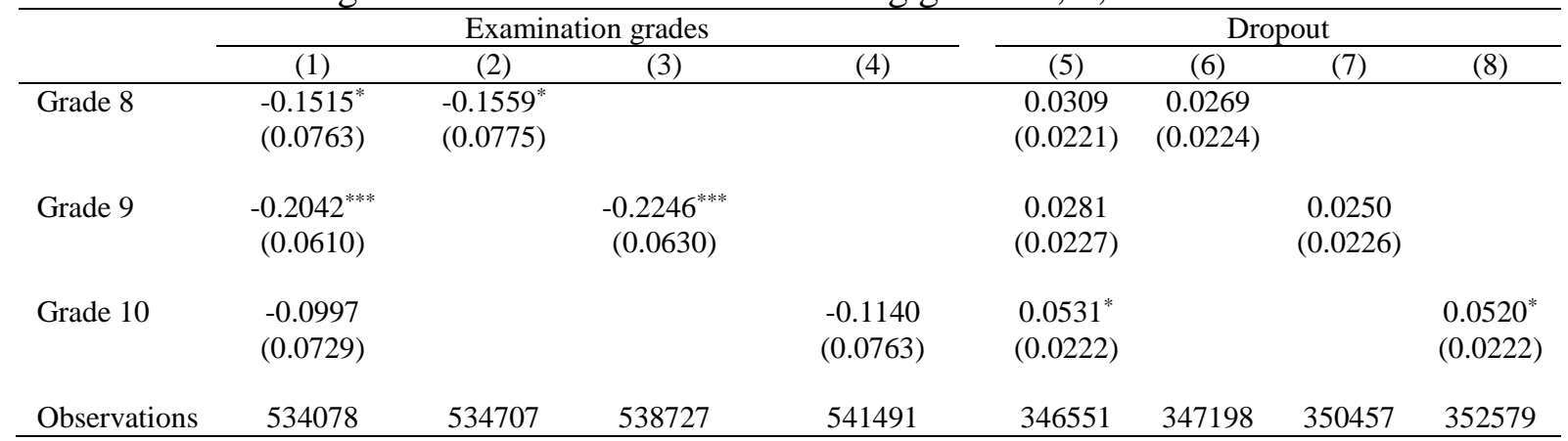

Note: Standard errors clustered at schools in parentheses. All models with school fixed effects, individual controls, and teacher controls.

${ }^{*} p<0.05,{ }^{* *} p<0.01,{ }^{* * *} p<0.001$ 
Table A6: Mean earnings rank at age 32-36 by educational attainment.

(1)

\begin{tabular}{lc} 
& Earnings rank \\
\hline Lower secondary education or lower & $37.3977^{* * *}$ \\
& $(0.0684)$ \\
Upper secondary education & $50.6056^{* * *}$ \\
& $(0.0619)$ \\
Higher education & $60.3919^{* * *}$ \\
& $(0.0646)$ \\
Observations & 529700 \\
\hline
\end{tabular}

Note: Sample of parents born between 1965 and 1975. Education at age 30.

Standard errors in parentheses

${ }^{*} p<0.05,{ }^{* *} p<0.01,{ }^{* * *} p<0.001$

Table A7: Teacher absence exposure by parental background of the student and immigrant background of the student.

Teacher absence

Panel A: Parental earnings rank

$1-24^{\text {th }}$ Percentile

Ref.

$25-49^{\text {th }}$ Percentile

$-0.0002^{*}$

$50-74^{\text {th }}$ Percentile

$(0.0001)$

$50-74$ Percentile

$-0.0002$

$75-99^{\text {th }}$ Percentile

$-0.0008^{* * * * *}$

Constant

(0.0001)

$0.0478^{* * * *}$

(0.0001)

Observations

555280

Panel B: Parental education

Lower sec. educ.

Ref.

Upper sec. educ.

$-0.0003^{* *}$

(0.0001)

Higher educ.

$-0.0006^{* * * *}$

Constant

(0.0001)

$0.0480^{* * * *}$

(0.0001)

Observations

554616

Panel D: Immigrant background

Native

Ref.

$\begin{array}{lc}\text { Children of immigrants } & -0.0010^{* * * *} \\ & (0.0002) \\ \text { Constant } & 0.0476^{* * *} \\ & (0.0000)\end{array}$

Observations

555299

Note: Standard errors in parentheses. See Table 3 for description of parental earnings and parental education. ${ }^{*} p<0.05,{ }^{* *} p<0.01,{ }^{* * *} p<0.001$ 
Table A8: Effects of examination grades on school dropout.

\begin{tabular}{lccccc}
\hline & $(1)$ & $(2)$ & $(3)$ & $(4)$ & $(5)$ \\
& Dropout & Dropout & Dropout & Dropout & Dropout \\
\hline Examination grades & $-0.1544^{* * * *}$ & $-0.1545^{* * *}$ & $-0.1122^{* * * *}$ & $-0.0838^{* * * *}$ & $-.0725^{* * *}$ \\
& $(0.0007)$ & $(0.0012)$ & $(0.0028)$ & $(0.0121)$ & $(0.0144)$ \\
Individual controls & & & & & \\
$\begin{array}{l}\text { School fixed effects } \\
\text { Siblings fixed effects }\end{array}$ & Yes & Yes & Yes & & \\
$\begin{array}{l}\text { Twin pair fixed effects } \\
\text { Same-sex twin pair fixed effects }\end{array}$ & & Yes & Yes & & \\
Observations & & & & Yes & \multirow{2}{*}{ Yes } \\
\hline
\end{tabular}

Note: Siblings are defined as individuals with the same biological mother. Standard errors in parentheses, with conventional standard errors in (1), standard errors clustered at schools in (2), and standard errors clustered by mother in (3)-(5).

${ }^{*} p<0.05,{ }^{* *} p<0.01,{ }^{* * *} p<0.001$

Table A9: Percent reduction in the socioeconomic dropout gap in a hypothetical setting without teacher absence.

\begin{tabular}{lcccc}
\hline & $\begin{array}{c}\text { Observed } \\
\text { dropout rate } \\
(\bar{Y})\end{array}$ & $\begin{array}{c}\text { Teacher absence } \\
\text { effect (from Table 2) }\end{array}$ & $\begin{array}{c}\text { Average } \\
\text { teacher absence } \\
(\text { TS })\end{array}$ & $\begin{array}{c}\text { Hypothetical dropout } \\
\text { without absence }\end{array}$ \\
\hline Low-income children & .4480 & .1942 & .0502 & .4383 \\
High-income children & .1568 & -.0521 & .0504 & .1594 \\
\hline Non
\end{tabular}

Note: Hypothetical dropout rate without absence is calculated as: $\bar{Y}-\delta * T S$. The observed gap is .291 , while the hypothetical dropout gap without absence is .2789 . The percent reduction is calculated as $(1-.2789 / .291) * 100=4.2$. 
Table A10: Teacher absence effect on examination grades by parental earnings and education in value-added models.

(1) (2)

\section{Panel A:}

Teacher absence

$-0.9104^{* *}-0.7520^{*}$

Parental earnings rank

$$
\text { * 1-24 }{ }^{\text {th }} \text { Percentile }
$$

Ref. Ref.

* 25-49 ${ }^{\text {th }}$ Percentile

$0.3680-0.1192$

* 50-74 ${ }^{\text {th }}$ Percentile

$(0.2911) \quad(0.2106)$

$0.3024-0.2634$

* 75-99 $9^{\text {th }}$ Percentile

(0.2672) (0.2068)

$0.2216 \quad 0.0515$

(0.3192) (0.2538)

Pre-academic achievement

$0.6793^{* * *}$

(0.0024)

Panel B:

Teacher absence

$-0.6217 \quad-0.6004$

(0.3985) (0.3521)

Parental education

* Lower sec. educ. or lower

Ref. Ref.

* Upper sec. educ.

$-0.1711 \quad-0.2549$

* Tertiary education

$\begin{array}{ll}(0.3247) \quad(0.2839) \\ 0.0129 & -0.2899\end{array}$

$0.0129 \quad-0.2899$

(0.3375) (0.2738)

Pre-academic achievement

$0.6793^{* * *}$

(0.0024)

Panel C:

Teacher absence

$-0.7616^{*}-0.7854^{* *}$

(0.3121) (0.2735)

Parental earnings rank

* $1-49^{\text {th }}$ Percentile

Ref. Ref.

* 50-99 ${ }^{\text {th }}$ Percentile

$0.0276 \quad-0.0278$

$(0.2101) \quad(0.1615)$

Parental education

* No Tertiary education

Ref. Ref.

* Tertiary education

$0.1348 \quad-0.0854$

(0.2271) (0.1706)

Pre-academic achievement

Observations

$231970 \quad 231970$

Note: Standard errors clustered at school level in parentheses. All models with school fixed effects, individual controls, and teacher controls. Estimates in panels are from different models. Parental earnings rank is defined as the percentile rank of children based on parental earnings relative to children in the same graduation cohort, including those with zero earnings. Parental education refers to the highest achievement of the two parents. ${ }^{*} p<0.05,{ }^{* *} p<0.01,{ }^{* * *} p<0.001$ 


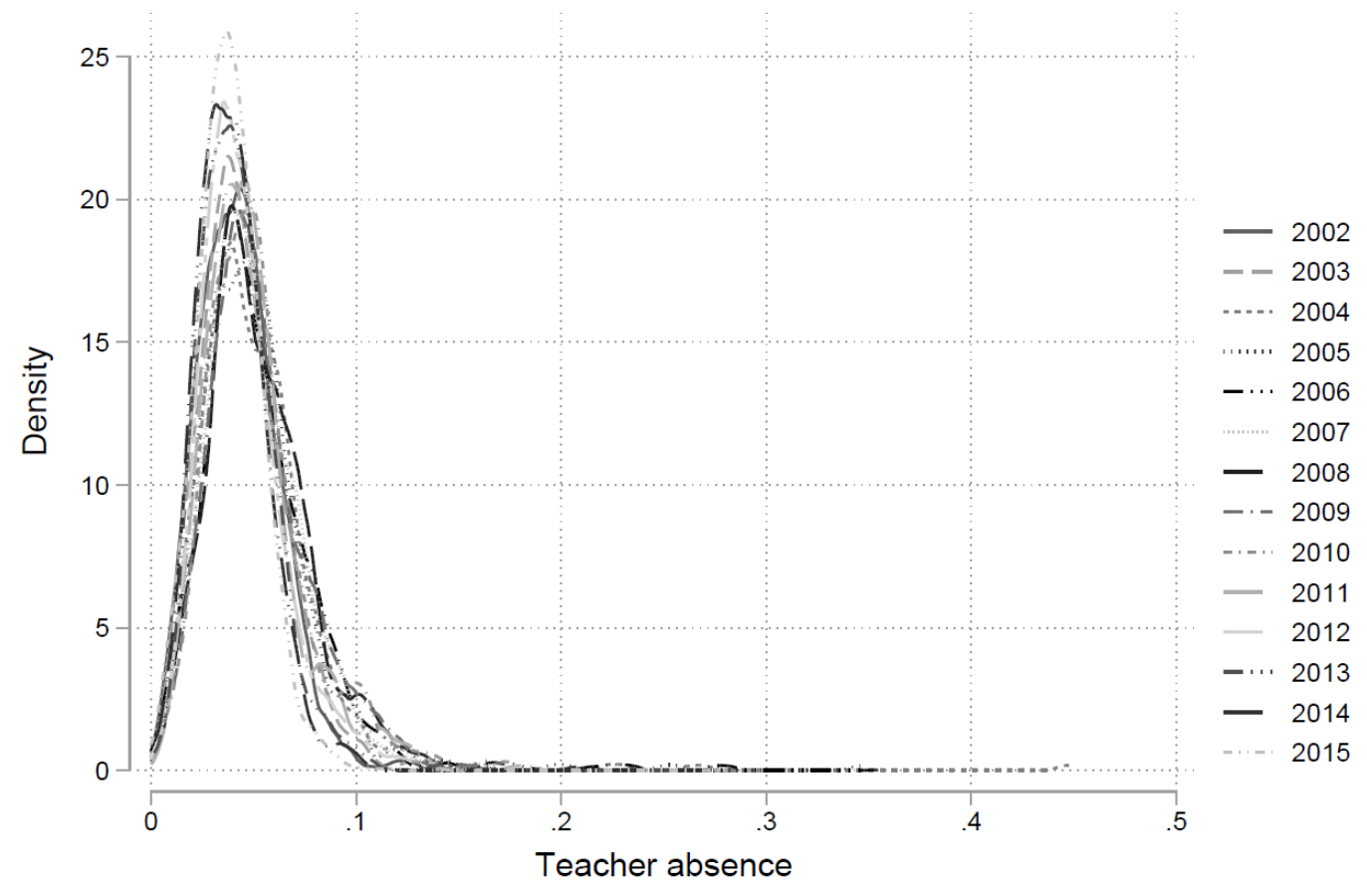

Figure A1: Density of teacher absence by year of graduation.

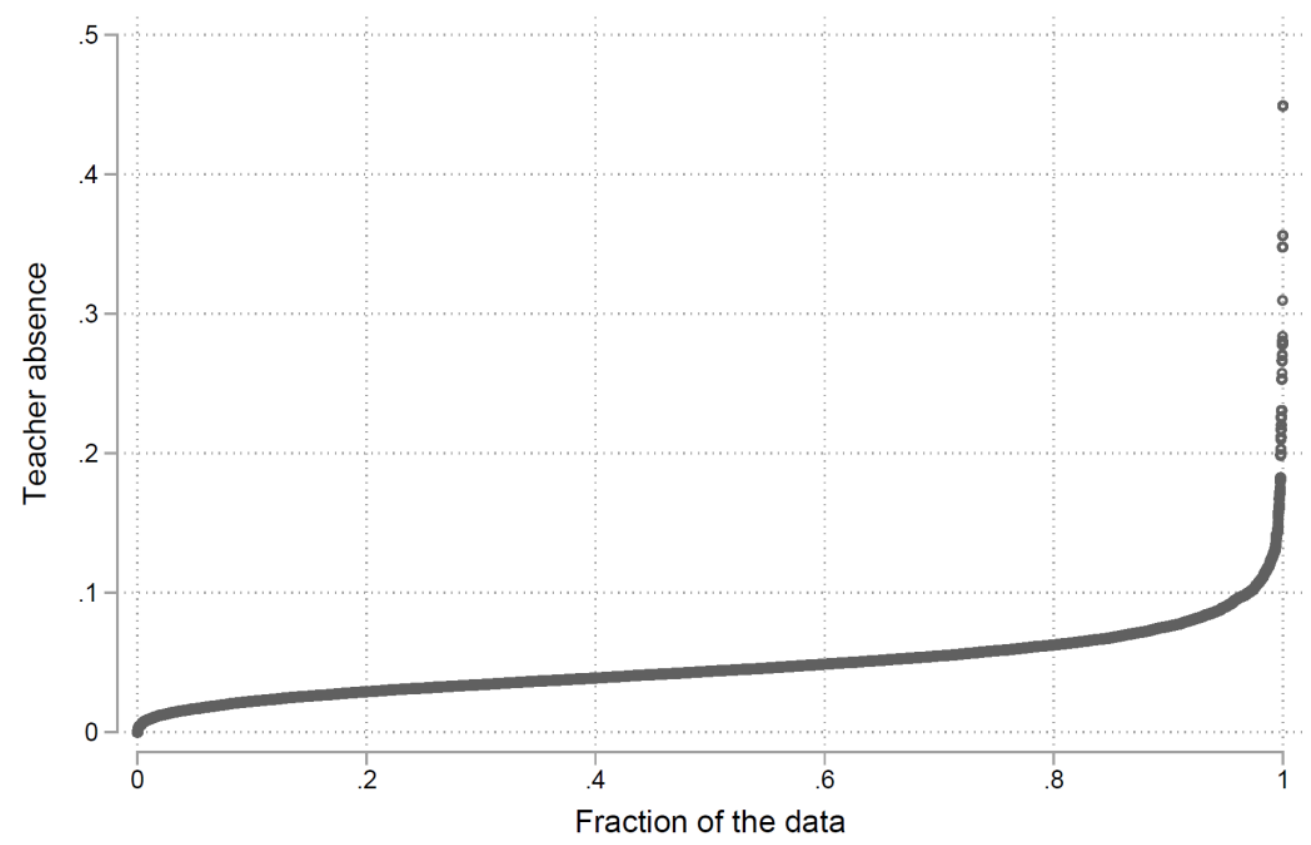

Figure A2: Quantile-plot showing the fraction of data with teacher absence at a given level. 

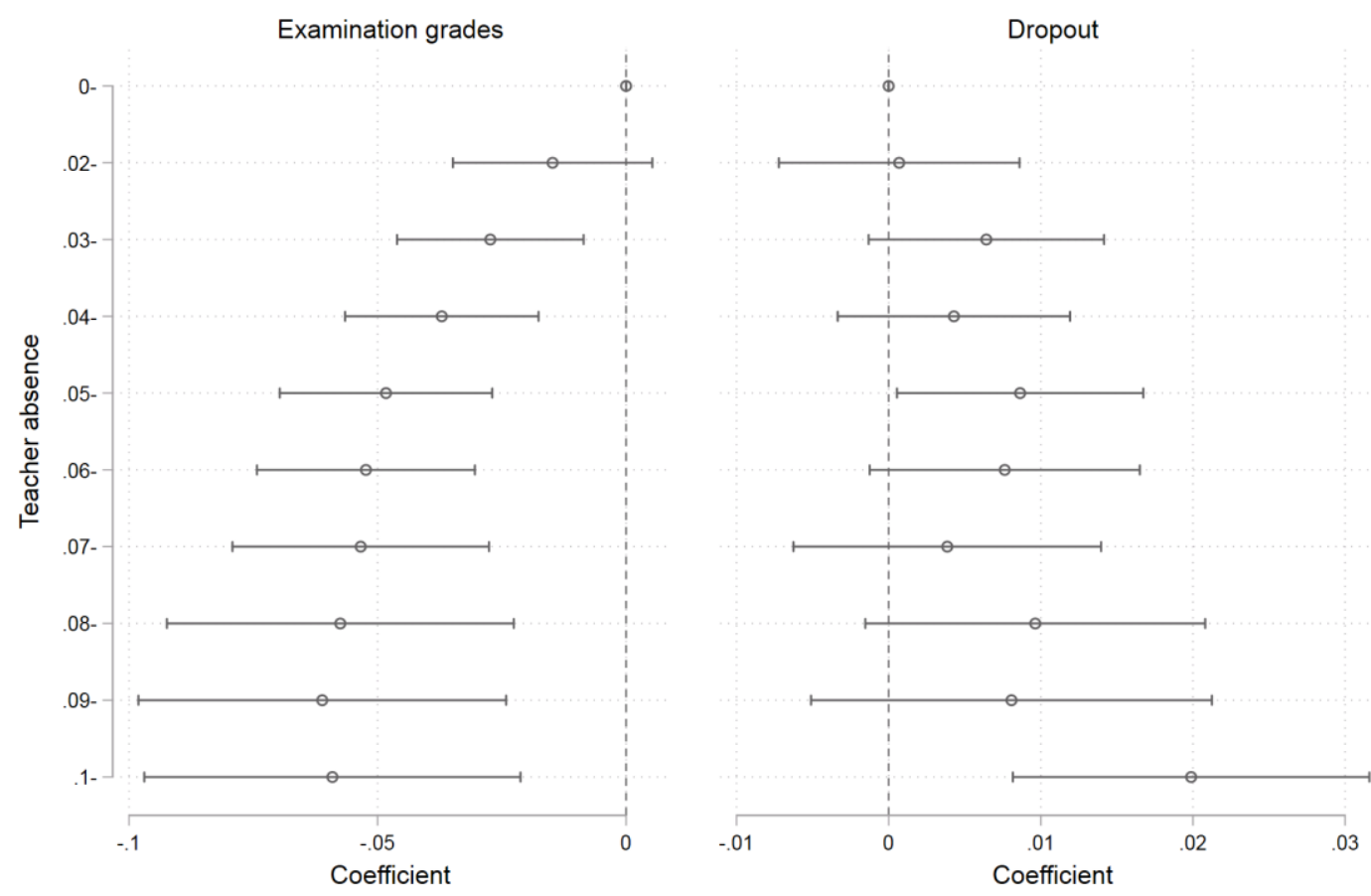

Figure A3: Non-linear effects of teacher absence on dropout and examination grades with $95 \%$ CI.

Note: The teacher absence variable is grouped in 10 groups and included as dummies in a school fixed effects model.

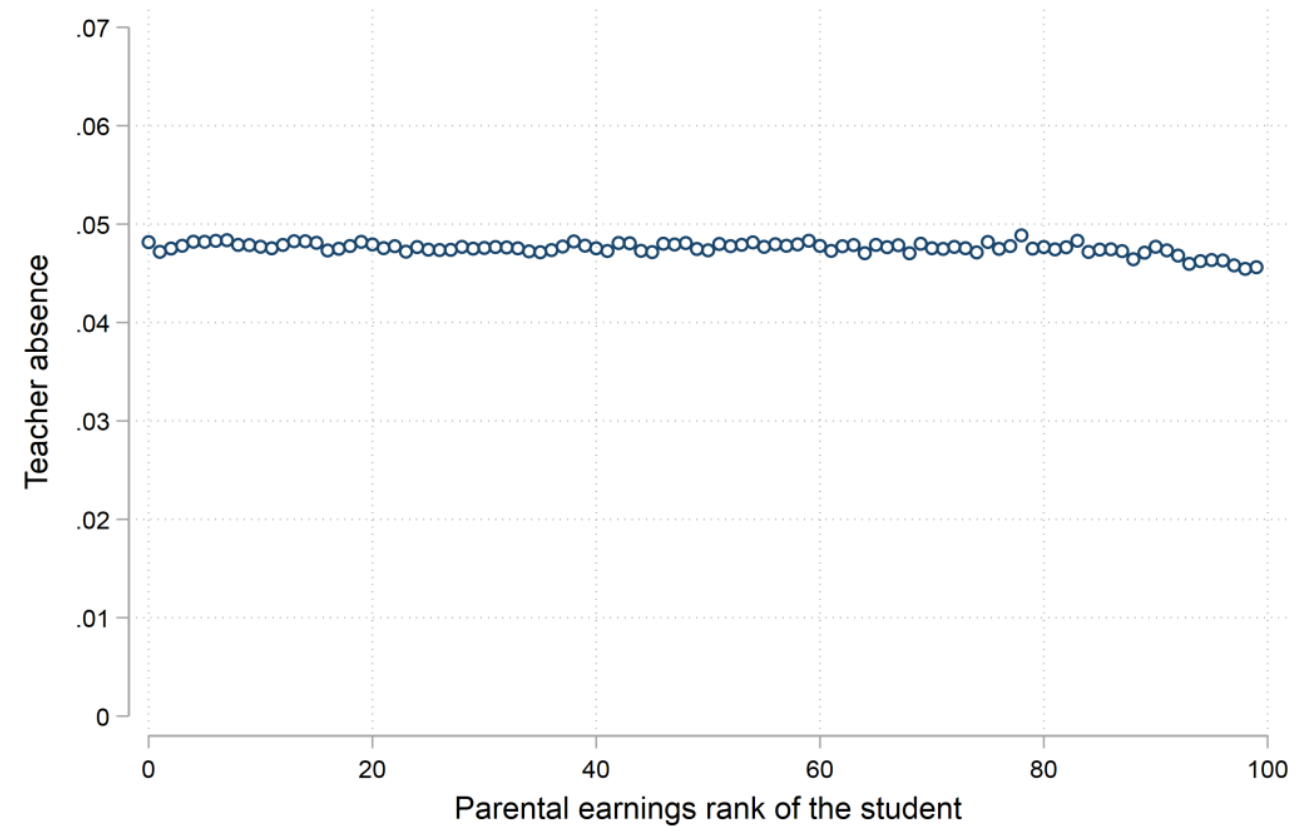

Figure A4: Bivariate association between parental earnings rank of the student and teacher absence. 

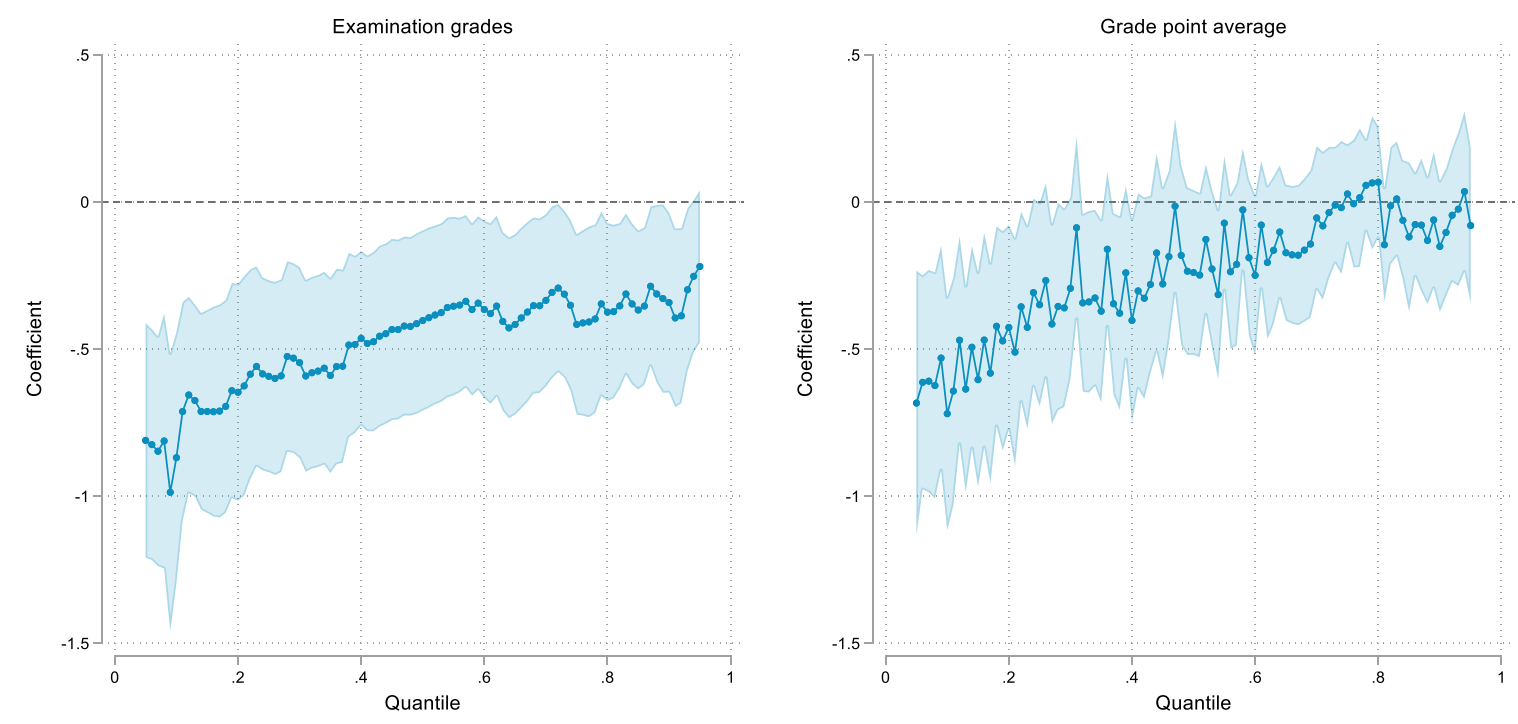

Figure A5: Effects of teacher absence on examination grades and grade point average across the outcome distributions.

Note: Coefficients are estimated using RQR. Examination grades are artificially smoothed but not grade point average.

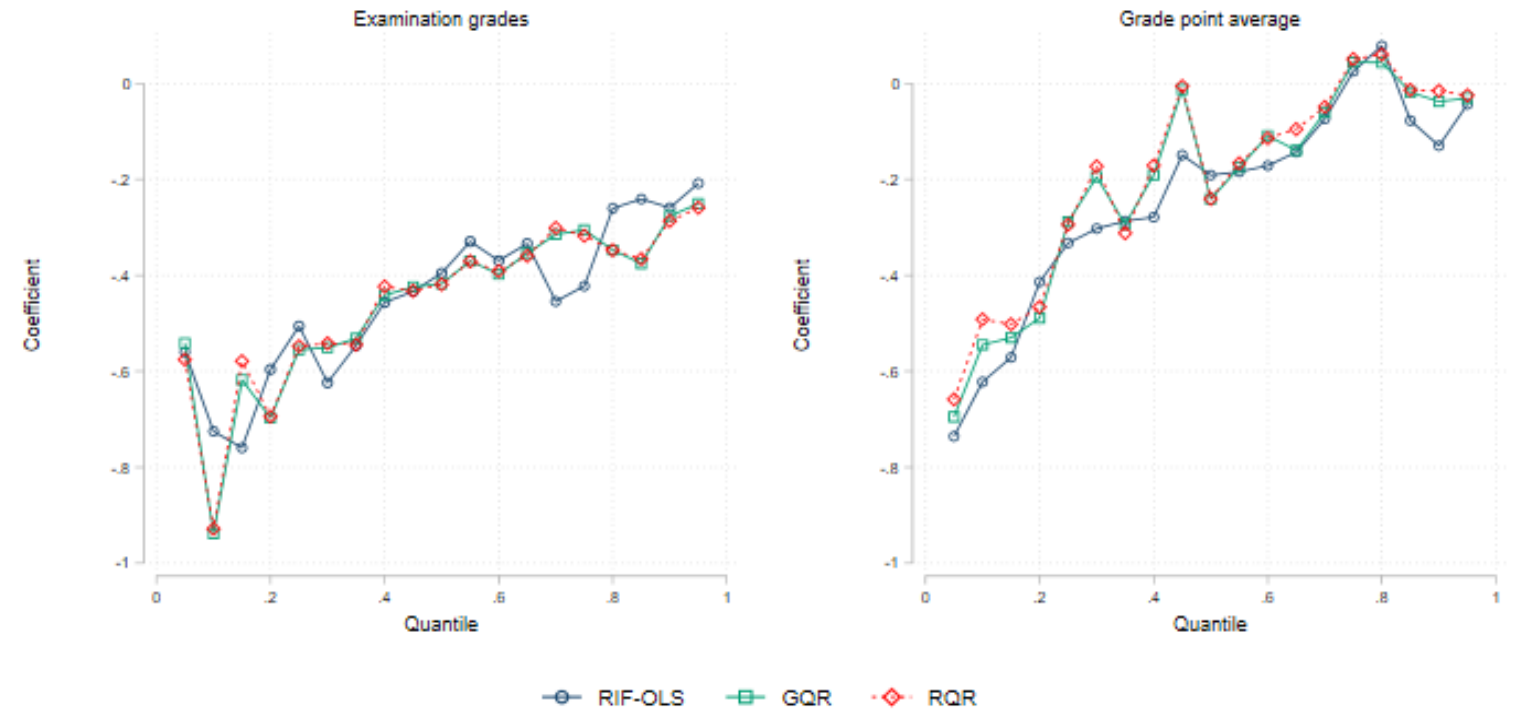

Figure A6: Effects of teacher absence on examination grades and grade point average using $\mathrm{RQR}$, generalized quantile regression (GQR), and unconditional quantile regression (RIFOLS).

Note: In RIF-OLS, the kernel density estimate is oversmoothed for examination grade because of heaping, but not for grade point average. To smooth the examination grades variable in GQR and RQR, we add uniform noise to jitter the data (Machado and Silva 2005) using a uniform distribution over the interval [-0.5, 0.5]. The GQR model is estimated using the user-written Stata command genqreg with dummies for school ID. 


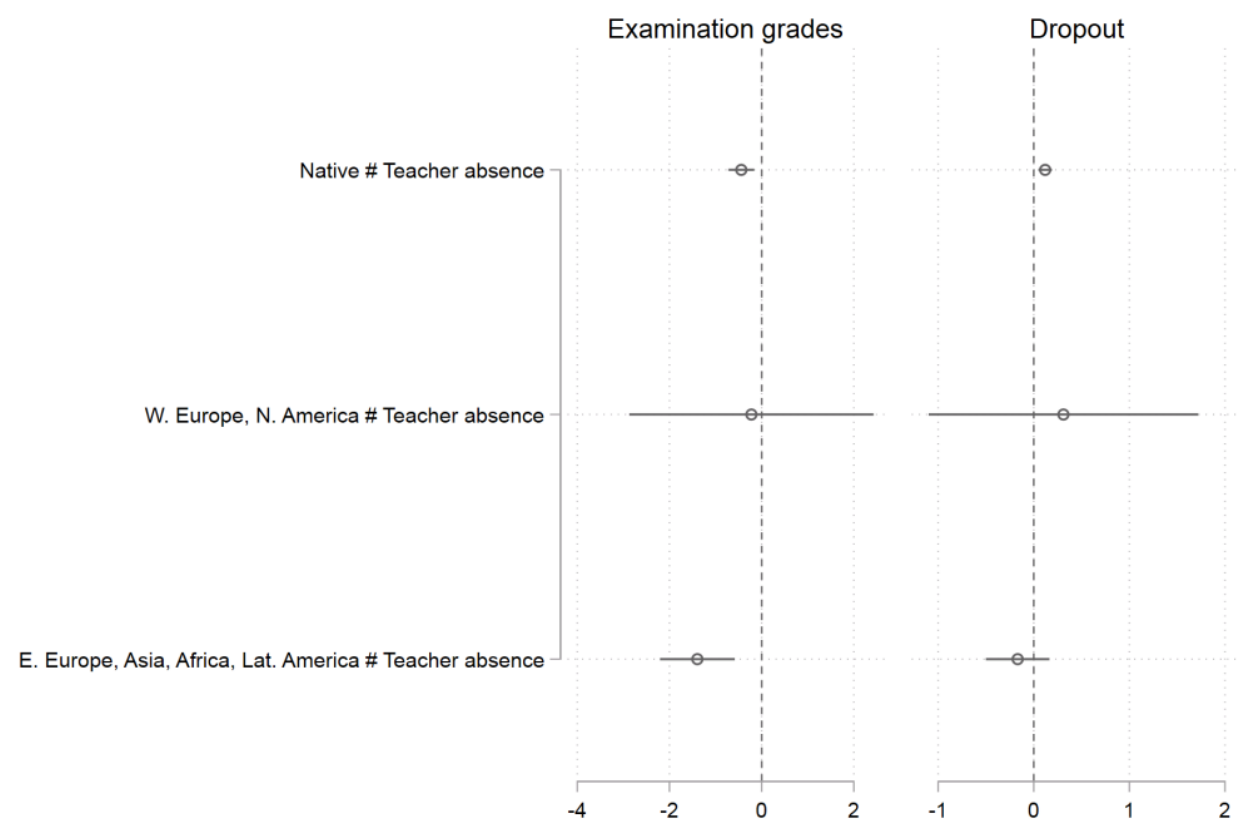

Figure A7: Effects of teacher absence by region of origin.

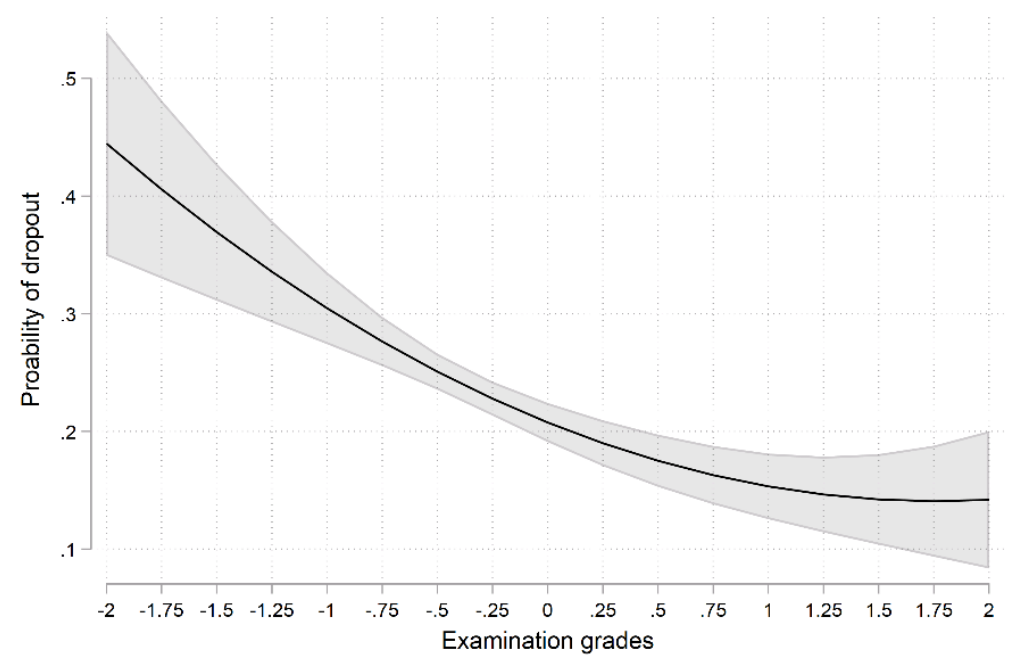

Figure A8: Association between examination grades and dropout in a same-sex twin fixed effects model.

Note: The predicted probability of dropout is based on a linear probability model that includes examination grades, examination grades squared, same-sex twin pair fixed effects, and cohort fixed effects. Twins are defined as individuals born in the same calendar month by the same biological mother. Standard errors clustered at mothers. See Appendix Table A8 for estimated association between examination grades and dropout without twin pair fixed effects. 

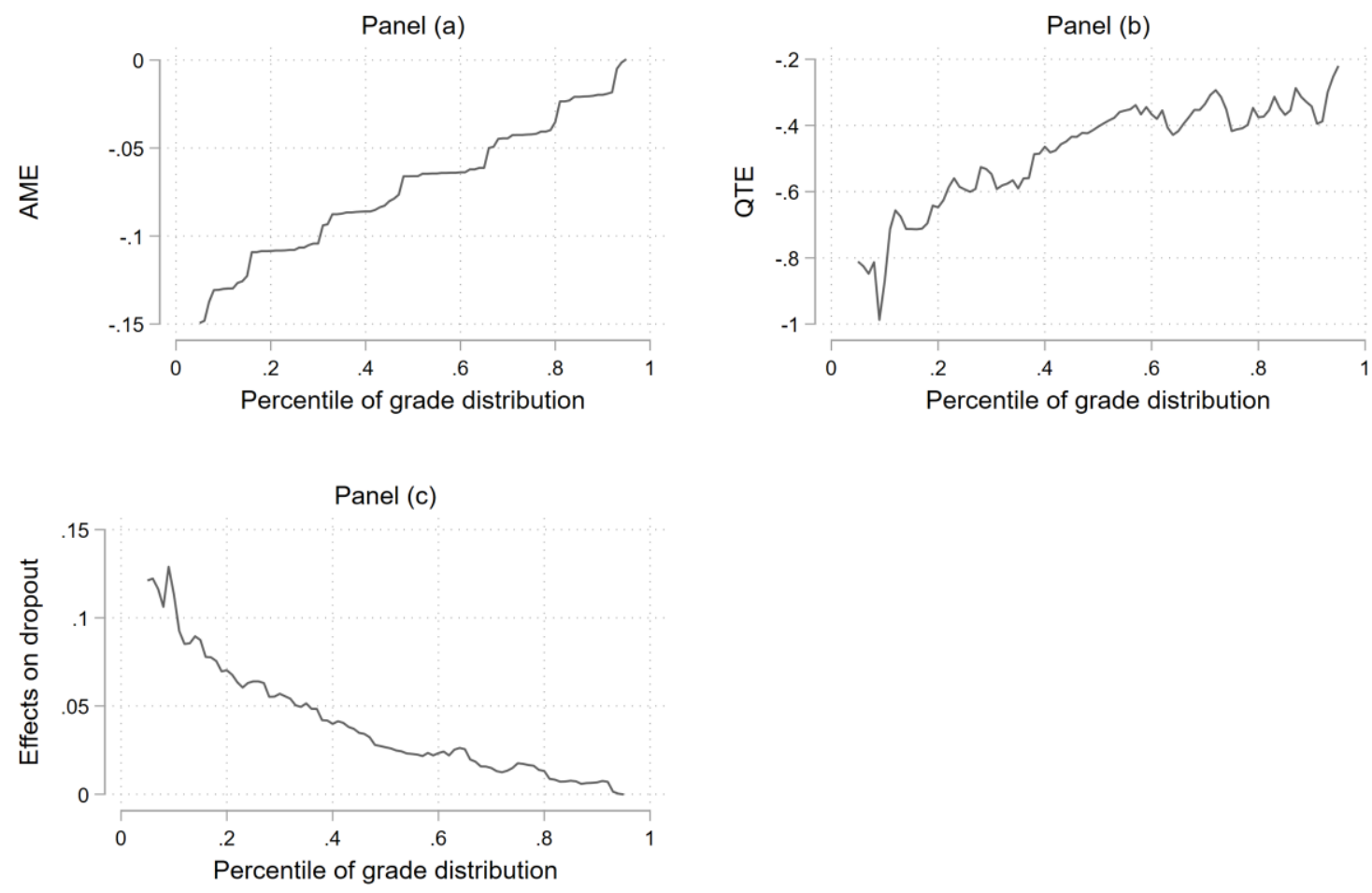

Figure A9: Product method to suggest how much of the teacher absence effects on dropout is explained by examination grades.

Note: Panel (a) display the average marginal effects (AME) calculated based on a linear probability model of the effects of examination grades and its squared term on school dropout, using a sample of same-sex twins with a twin pair fixed effect and cohort fixed effects. Subsequently, AME is calculated at various percentiles of the grade distribution. Panel (b) includes the quantile treatment effects, and is identical to the estimates shown in Figure 2. Panel (c) display the product of the coefficients in Panel (a) and Panel (b), and shows the calculated effects of teacher absence on dropout - mediated through examination grades - for students in different part of the grade distribution. The average of the calculated effects of teacher absence on dropout in panel (c) is 0.0399 . 


\section{Online Appendix B: Robustness checks}

When concluding on cause-and-effect relationships, it is crucial to account for factors that may confound the estimates. Based on the school fixed effects model, we find that teacher absence impairs students' academic achievements and subsequently increases school dropout risk. Taking account of time-invariant school characteristics (i.e., school fixed effects) is seemingly important as the estimated effects of teacher absence without these fixed effects are considerably larger (Table 2). Still, a concern is that the within-school variation in teacher absence could be (partly) caused by variation in the share of students with behavioral and academic problems, even if we condition on time-variant student family background characteristics. This online appendix investigates this concern empirically by using a subset of the overall cohorts, for whom we have access to richer data. The smaller sample size in most of these sensitivity analyses reduces the precision of the estimated effects. For that reason, we choose to focus on the average impact of teacher absence.

We explore the robustness of the results from two complementary angles: by studying whether potential confounders influence teacher absence (i.e., with teacher absence as an outcome, Table B1) and comparing the estimated effects of teacher absence with and without the potential confounder (Tables B2-B3). The benefit of the former approach is that it examines the selection mechanisms we are interested in, and we need to be less concerned about whether the confounders are adequately measured. The latter approach's advantage is that it directly suggests the size of bias in the teacher absence coefficient, but measurement error or incompleteness in the observed proxy matters. As an illustration, child delinquents' classroom behavior may influence teachers' absence, allowing us to test the concern of reverse causality. Still, as child delinquency is rare, it is a poor proxy for general classroom behavior, and controlling for child delinquency is unlikely to influence estimates notably. 
Table B1: Variation in teacher absence

(1)

Teacher absence

\section{Panel A:}

Pre-treatment test score

0.000053

(Mean=0.017, SD=0.883)

$(0.000058)$

Observations

Panel B:

Charged by age of 12

0.000176

(Mean=0.010, SD=0.098)

$(0.000300)$

Observations

549916

Panel C:

Poor school behavior by end of $10^{\text {th }}$ grade

(Mean=0.023, SD=0.149)

0.000136

$(0.000357)$

Observations

235430

Panel D:

Students GP visits grade 8-10 $0.000014^{* *}$

(Mean=6.672, $\mathrm{SD}=6.620)$

Observations

213387

Note: Standard errors clustered at school level in parentheses. All models with school fixed effects, individual controls, and teacher controls. Estimates in panels are from different models.

${ }^{*} p<0.05,{ }^{* *} p<0.01,{ }^{* * *} p<0.001$

From 2007 and onwards, every student in Norway must undergo nationwide standardized testing in reading, math, and English. The $8^{\text {th }}$-grade test is basically an entry test since it occurs during the fall semester, shortly after the students start. Using the average of these national tests across subjects as a predictor, we do not find any indications of higher teacher absence in cohorts (within schools) with lower entry-test scores (panel A in Table B1). This suggests that reverse causality or simultaneity bias is not a major concern in our school fixed effects model, which aligns with previous literature using teacher fixed effects (Herrmann and Rockoff 2012). 
Table 6: Robustness checks

\begin{tabular}{|c|c|c|c|c|c|c|c|c|c|c|c|c|}
\hline & \multirow{2}{*}{\multicolumn{2}{|c|}{$\begin{array}{c}\begin{array}{c}\text { Value-added } \\
\text { model }\end{array} \\
\text { Examination grades }\end{array}$}} & \multirow{2}{*}{\multicolumn{2}{|c|}{$\begin{array}{c}\text { Common health shock } \\
\text { controls }\end{array}$}} & \multicolumn{8}{|c|}{$\begin{array}{l}\text { Behavioral problems } \\
\text { controls }\end{array}$} \\
\hline & & & & & \multicolumn{4}{|c|}{ Examination grades } & \multicolumn{4}{|c|}{ School dropout } \\
\hline & (1) & (2) & (3) & (4) & (5) & (6) & (7) & (8) & (9) & (10) & (11) & (12) \\
\hline Teacher absence & $\begin{array}{l}-0.6881^{*} \\
(0.2835)\end{array}$ & $\begin{array}{l}-0.8454^{* * *} \\
(0.2474)\end{array}$ & $\begin{array}{l}-0.8922^{* * * *} \\
(0.2521)\end{array}$ & $\begin{array}{l}-0.8723^{* * * *} \\
(0.2533)\end{array}$ & $\begin{array}{l}-0.4625^{* *} \\
(0.1431)\end{array}$ & $\begin{array}{l}-0.4620^{* *} \\
(0.1434)\end{array}$ & $\begin{array}{l}-0.7317^{* * *} \\
(0.2384)\end{array}$ & $\begin{array}{l}-0.7212^{* *} \\
(0.2283)\end{array}$ & $\begin{array}{l}0.1109^{* *} \\
(0.0361)\end{array}$ & $\begin{array}{l}0.1105^{* *} \\
(0.0363)\end{array}$ & $\begin{array}{l}0.2619^{*} \\
(0.1266)\end{array}$ & $\begin{array}{l}0.2597^{*} \\
(0.1275)\end{array}$ \\
\hline Pre-academic achievement & & $\begin{array}{l}0.6795^{* * *} \\
(0.0024)\end{array}$ & & & & & & & & & & \\
\hline Students GP visits grade $8-10$ & & & & $\begin{array}{c}-0.0082^{* * * *} \\
(0.0004)\end{array}$ & & & & & & & & \\
\hline Criminal charges by age 12 & & & & & & $\begin{array}{c}-0.3604^{* * * *} \\
(0.0127)\end{array}$ & & & & $\begin{array}{l}0.1650^{* * *} \\
(0.0078)\end{array}$ & & \\
\hline Poor school behavior grade 10 & & & & & & & & $\begin{array}{c}-0.8300^{* * * *} \\
(0.0137)\end{array}$ & & & & $\begin{array}{l}0.3901^{* * *} \\
(0.0081)\end{array}$ \\
\hline Observations & 232193 & 232193 & 205267 & 205267 & 533986 & 533986 & 228693 & 228693 & 346551 & 346551 & 117148 & 117148 \\
\hline
\end{tabular}

Note: Standard errors clustered at school level in parentheses. All models with school fixed effects, individual controls, and teacher controls. Sample size varies because of data availability.

${ }^{*} p<0.05,{ }^{* *} p<0.01,{ }^{* * *} p<0.001$ 
Table 7: Robustness checks

\begin{tabular}{|c|c|c|c|c|c|c|c|c|c|}
\hline & \multicolumn{5}{|c|}{ Examination grades } & \multicolumn{4}{|c|}{ School dropout } \\
\hline & (1) & (2) & (3) & (4) & $(5)$ & (6) & (7) & (8) & (9) \\
\hline Teacher absence & $\begin{array}{c}-0.5955^{* *} \\
(0.1910)\end{array}$ & $\begin{array}{c}-0.5814^{* *} \\
(0.1893)\end{array}$ & $\begin{array}{c}-0.5873^{* *} \\
(0.1896)\end{array}$ & $\begin{array}{c}-0.5922^{* *} \\
(0.1906)\end{array}$ & $\begin{array}{c}-0.5773^{* *} \\
(0.1885)\end{array}$ & $\begin{array}{c}0.2405^{*} \\
(0.1006)\end{array}$ & $\begin{array}{c}0.2531^{*} \\
(0.0994)\end{array}$ & $\begin{array}{c}0.2406^{*} \\
(0.0989)\end{array}$ & $\begin{array}{c}0.2524^{*} \\
(0.0992)\end{array}$ \\
\hline Classroom noise grade 10 & & $\begin{array}{c}-0.1124^{* * * *} \\
(0.0155)\end{array}$ & & & $\begin{array}{c}-0.0886^{* * * *} \\
(0.0157)\end{array}$ & & & & \\
\hline School wellbeing grade 10 & & & $\begin{array}{c}0.1280^{* * * *} \\
(0.0146)\end{array}$ & & $\begin{array}{c}0.1066^{* * * *} \\
(0.0166)\end{array}$ & & $\begin{array}{c}-0.0411^{* * *} \\
(0.0078)\end{array}$ & & $\begin{array}{c}-0.0388^{* * *} \\
(0.0084)\end{array}$ \\
\hline School bullying grade 10 & & & & $\begin{array}{c}-0.3048^{* * *} \\
(0.0680)\end{array}$ & $\begin{array}{l}-0.0216 \\
(0.0754)\end{array}$ & & & $\begin{array}{l}0.0913^{* *} \\
(0.0297)\end{array}$ & $\begin{array}{c}0.0203 \\
(0.0323)\end{array}$ \\
\hline Observations & 305512 & 305512 & 305512 & 305512 & 305512 & 154972 & 154972 & 154972 & 154972 \\
\hline
\end{tabular}

Note: Standard errors clustered at school level in parentheses. All models include school fixed effects, individual controls, and teacher controls. Measures of school

environment are obtained from an annual nation-wide survey among all $10^{\text {th }}$ graders in Norway (>90\% response rate), which we can match to our register data on the schoolcohort level for cohorts 2007-2012 and cohorts 2014-2015. Student-reported frequency of classroom noise is measured on a five-point scale (1=fully agree with classroom order, $5=$ fully disagree with classroom order), and is standardized to have a pupil-weighted mean of zero and standard deviation of 1 . Student-reported school wellbeing is measured on a five-point scale (1=does not enjoy school very much, $5=$ enjoy school very much), and is standardized to have a pupil-weighted mean of zero and standard deviation of 1 . School bullying measures the share of students that report being bullied at least 2-3 times a month, which in our sample is 7.9 percent of the students. For the cohorts 2007-2009, we do not observe the indicator classroom noise, and replace missing values with zero for these cohorts and include a dummy for missing values. ${ }^{*} p<0.05,{ }^{* *} p<0.01,{ }^{* * *} p<0.001$ 
Further, we test the concern of reverse causality and simultaneity bias more explicitly in Table B2, where we re-estimate our main results for a subset of the data (for which $8^{\text {th }}$-grade test scores are available) using a value-added school fixed effects model. Relative to the coefficients' precision, the point estimates are similar whether entry tests are controlled for or not; the coefficient difference between columns (1) and (2) is about $60 \%$ of the standard error. Finally, our identifying assumption is supported by $8^{\text {th }}$-grade test scores as a placebo outcome since there is no significant correlation between these scores and subsequent teacher absence for the same cohort (Appendix Table B4).

Table B4: Placebo outcome.

\begin{tabular}{lc}
\hline & $\begin{array}{c}\text { Pre-treatment } \\
\text { test score } \\
(1)\end{array}$ \\
\hline Teacher absence & 0.1898 \\
& $(0.2033)$ \\
& \\
Observations & 238133
\end{tabular}

Note: Standard errors clustered at school level in parentheses. All models with school fixed effects, individual controls, and teacher controls.

${ }^{*} p<0.05,{ }^{* *} p<0.01,{ }^{* * *} p<0.001$

There is a potential concern that student behavior or an unhealthy school environment causes teacher absence and poor student performance. About 1 percent of the students have received a criminal charge before entering lower secondary school (by the age of 12), which can be taken as an indicator of child behavioral problems. ${ }^{9} \mathrm{We}$ find that the rate of teacher absence is similar for students with criminal charges by the age of 12 as for other students (Panel B in Table B1). It is also reassuring that we find no association between our teacher absence measure and poor marks in order and conduct in grade 10 (Panel C in Table B1). In our sample, $2.3 \%$ of the students obtain poor marks in order and conduct, which measures behavior such as being late to class, not doing the homework, being violent, and cheating on

\footnotetext{
${ }^{9}$ These criminal charges do not result in stays in a juvenile detention center, but the children are likely to be transferred to the child welfare services.
} 
tests. As this is graded in the last year of lower secondary schools, any positive association could be interpreted as a combination of a causal effect of teacher absence on behavioral problems and a causal effect of behavioral problems on teacher absence. Finding no association suggests that confounding because of time-variant (unobserved) student behavioral problems is not a major issue in the school fixed effects models. Again, we test this more explicitly in Table 6, and the inclusion of behavioral problem indicators does not change the estimated effects of teacher absence (columns 5-12).

Finally, we explore the importance of an unhealthy school environment using studentreported school environment measures, available from an anonymous annual nationwide survey among all $10^{\text {th }}$ graders in Norway for cohorts after 2007. We find that more classroom noise, less school well-being, and more school bullying are associated with poorer examination grades and more dropout (Table B2). However, controlling for these variables does not change the estimated effects of teacher absence, leaving us less concerned about confounding school factors.

Besides reverse causality, another concern in the school fixed effects model is a common shock that increases teacher absence and directly affects students' learning. For some student cohorts, we can observe their visits to their general practitioner (GP) from the register of Control and Payment of Health Reimbursement (Torvik et al. 2018). Under the assumption that the variation in student GP visits within schools is a proxy variable for common health shocks, these GP visits could indicate to what extent such shocks bias our main results. Looking at the results in panel D of Table 5, we see that the number of GP visits is weak but positively associated with teacher absence. However, the effect is trivial - a 1SD increase in the number of GP visits increases the teacher absence rate by 0.00009 - and the estimated effects of teacher absence on standardized examination grades are nearly identical with and without student GP visits as a control (columns 3-4 in Table B2). 
Since dropout rates differ by region in Norway, we are concerned about correlated trends in the outcome variables and the treatment variable that are regionally specific. Thus, we have checked whether the results are robust to including regional-specific cohort fixed effects (19 counties). Concerning short-term academic achievements, the results are largely unaffected by the inclusion of school county-specific cohort fixed effects. The effects on dropout are more affected by county-specific cohort fixed effects, with point estimates reduced by roughly $20 \% .^{10}$ However, the precision is also reduced when including regional-specific cohort fixed effects, and the confidence intervals with the different specifications overlap (Appendix Figure B1).

Academic achievement

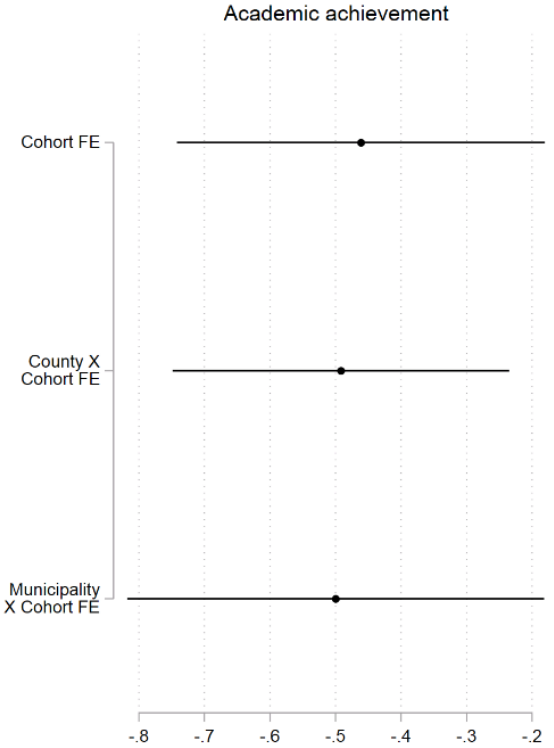

Dropout

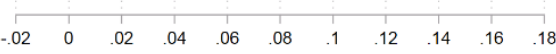

Figure B1: Effects of teacher absence controlling for cohort fixed effects, school county specific cohort fixed effects, and school municipality specific cohort fixed effects.

Note: The coefficient in the cohort fixed effects and school county specific cohort fixed effects are also shown in Table B5.

\footnotetext{
${ }^{10}$ As shown in Online Appendix Figure B1, including school municipality specific cohort fixed effects for the 286 school municipalities reduces the estimated effects of teacher absence on dropout by roughly $35 \%$ and renders the coefficient significant at the $9.3 \%$ level only.
} 
Table B5: Robustness checks including regional time trends for the 19 school counties.

$$
\text { Examination grades School dropout }
$$

\begin{tabular}{lcccc} 
& $(6)$ & $(7)$ & $(8)$ & $(9)$ \\
\hline Teacher absence & $-0.4612^{* *}$ & $-0.4917^{* *}$ & $0.1109^{* *}$ & $0.0893^{*}$ \\
& $(0.1430)$ & $(0.1308)$ & $(0.0361)$ & $(0.0357)$ \\
County cohort FE & & & & Yes \\
Observations & 534078 & 532167 & 346551 & 344582
\end{tabular}

Note: Standard errors clustered at school level in parentheses. All models with school fixed effects, individual controls, and teacher controls.

${ }^{*} p<0.05,{ }^{* *} p<0.01,{ }^{* * *} p<0.001$

Finally, the school fixed effects only account for stable between-school differences in teacher characteristics, student characteristics, and school resources. With a long observation window, the fixed effects estimator may produce biased estimates if schools systematically change over time in a way correlated with teacher absence. To meet this concern, we re-estimate the main results with a six-year rolling average, which for the latest cohorts coincides with the period we have information on entry tests (see above). The average teacher absence effect fluctuates somewhat across the cohorts, but there is no trend (Panel A and B in Online Appendix Figure B2). In contrast, there seems to be a decline in the socioeconomic gradients in the teacher absence effects on examination grades towards the end of our observation period. Unlike for the first nine cohorts, the parental earnings interaction coefficient is close to zero in the last six cohorts, which holds whether entry test scores are conditioned on or not (Panel C). However, the confidence intervals overlap for all cohorts, and no strong conclusion concerning time trends can be drawn from the data. 

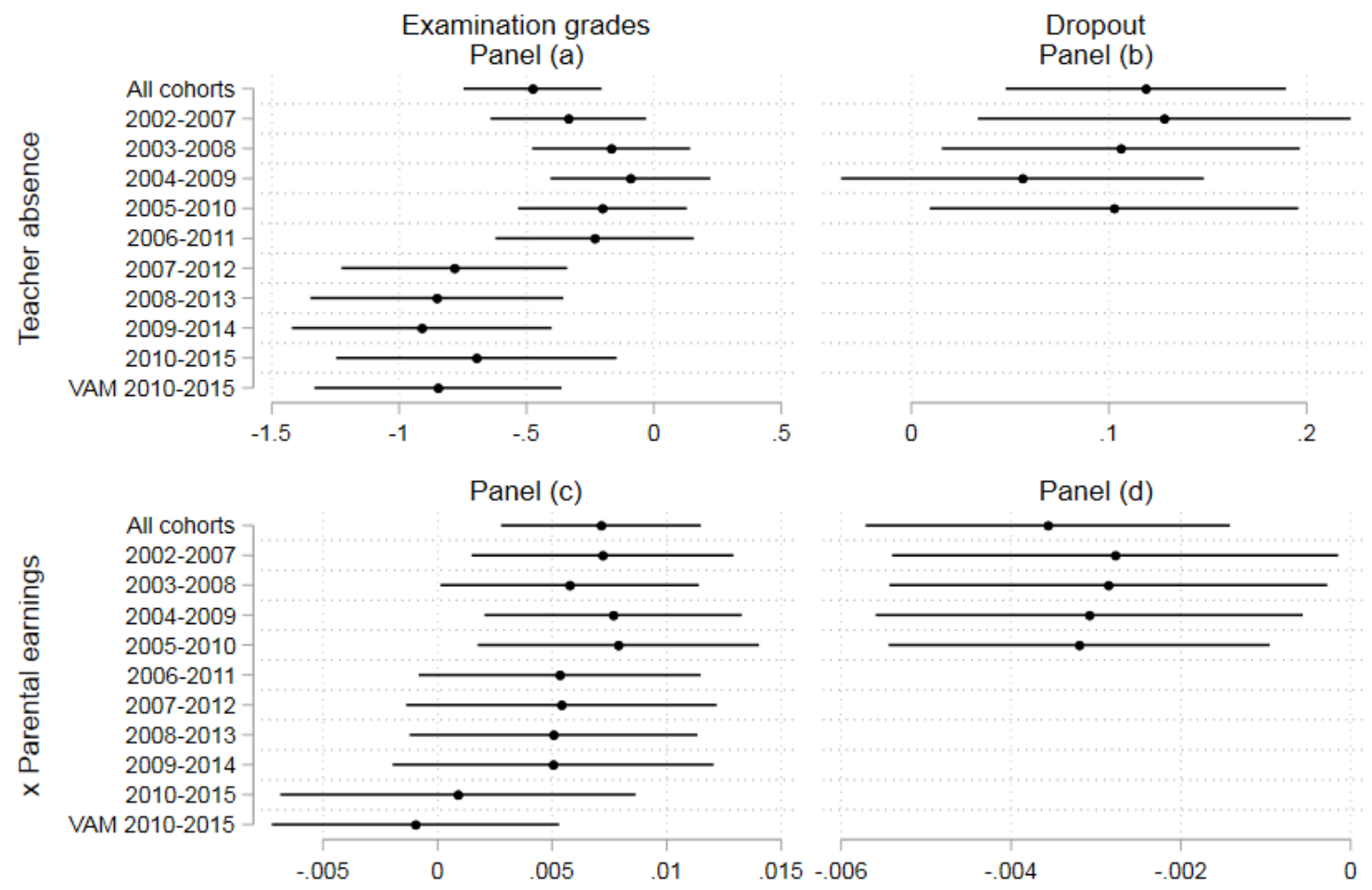

Figure B2: Socioeconomic gradients in teacher absence effects in six-year rolling averages compared to all available cohorts.

Note: The first row in each panel includes all available cohorts for the outcomes. The six-year rolling average estimates are estimated in separate regression analyses. The VAM model controls for the entry test score. The upper panels (a) and (b) show the main effect evaluated at the median of parental earnings, while the lower panels (c) and (d) show teacher absence interacted with ranked parental earnings. The parental earnings variable ranges from 0 (low parental earnings) to 99 (high parental earnings) and is centered at the median. 


\section{Online Appendix C: Data simulations}

This appendix simulates data to show that replacing the true teacher absence rate $\left(T_{s c}\right)$ with the error-ridden observed school-level teacher absence rate $\left(T S_{S c}\right)$ produce consistent estimates of the true effect, only less precisely estimated. We refer to these two absence rate variables as true and observed teacher absence in this appendix. Stata code to replicate the simulation results is included at the end of this appendix.

We construct 1000 lower secondary schools $s$, each with eight school cohorts $c$ of 20 individuals $i$ observed from grades $g 8$ through 10 . Then, we define teacher absence at the school-by-grade level as $T_{s c g}=.05+u_{s} *-0.01+e_{s c g}$, where $e_{s c g} \sim \operatorname{Bet} a(0.90,20)$ and $u_{s} \sim N(0,1)$ is an unobserved time-invariant school quality variable that reduces teacher absence. The true treatment variable is defined as $T_{s c}=T_{s 8}+T_{s 9}+T_{s 10} / 3$ and measure individuals' average exposure to teacher absence. The observed treatment variable is based on the school's average teacher absence across grades 8-10 $T S_{s c}=T S_{s c 8}+T S_{s c 9}+T S_{s c 10} / 3$, where $T S_{s c 8}$ is the school average across grades 8-10 the year the cohort attended grade $8, T S_{s c 9}$ is the school average the year the cohort attended grade 9 , and $T S_{s c 10}$ is the school average the year the cohort attended grade 10. Finally, the outcome in grade 10 is defined as $y_{i s c}=T_{s c} *$ $-.10+u_{s}+\varepsilon_{i s c}$, where $\varepsilon_{i s c} \sim N(0,1)$. The analysis data consists of one observation for each individual (in grade 10) $(\mathrm{N}=160,000)$, clustered in 1,000 schools and eight school cohorts.

Using a school fixed effects model, we compare the estimate of $\beta_{1}$ with that of $\delta_{1}$ from the following two models across 10,000 independent draws:

$$
\begin{gathered}
y_{i s c}=\beta_{0}+\beta_{1} T_{s c}+\alpha_{s}+\epsilon_{i s c} \\
y_{i s c}=\delta_{0}+\delta_{1} T S_{s c}+\alpha_{s}+\epsilon_{i s c}
\end{gathered}
$$


The results displayed in Table $\mathrm{C} 1$ and Figure $\mathrm{C} 1$ below demonstrate that replacing the true teacher absence rate with the average across school years produces the same coefficients. The coefficients of the true teacher absence and the error-ridden observed teacher absence are both close to -0.10 , which is the true effect (Appendix Table C1). However, when using the observed teacher absence variable, the standard deviation across the random draws is twice as high as when using the true teacher absence variable, reflecting the fact that the observed teacher absence variable produces less precise estimates. The precision penalty is also shown graphically in Appendix Figure C1; the variation in the coefficients across the random draws is much higher with the observed teacher absence variable than the true teacher absence variable.

Appendix Table C1: Average coefficient and standard deviation across 10,000 draws

\begin{tabular}{lll}
\hline & Coefficient & Standard deviation \\
\hline Observed teacher absence & -0.0995 & 0.2104 \\
True teacher absence & -0.1016 & 0.1076 \\
\hline
\end{tabular}

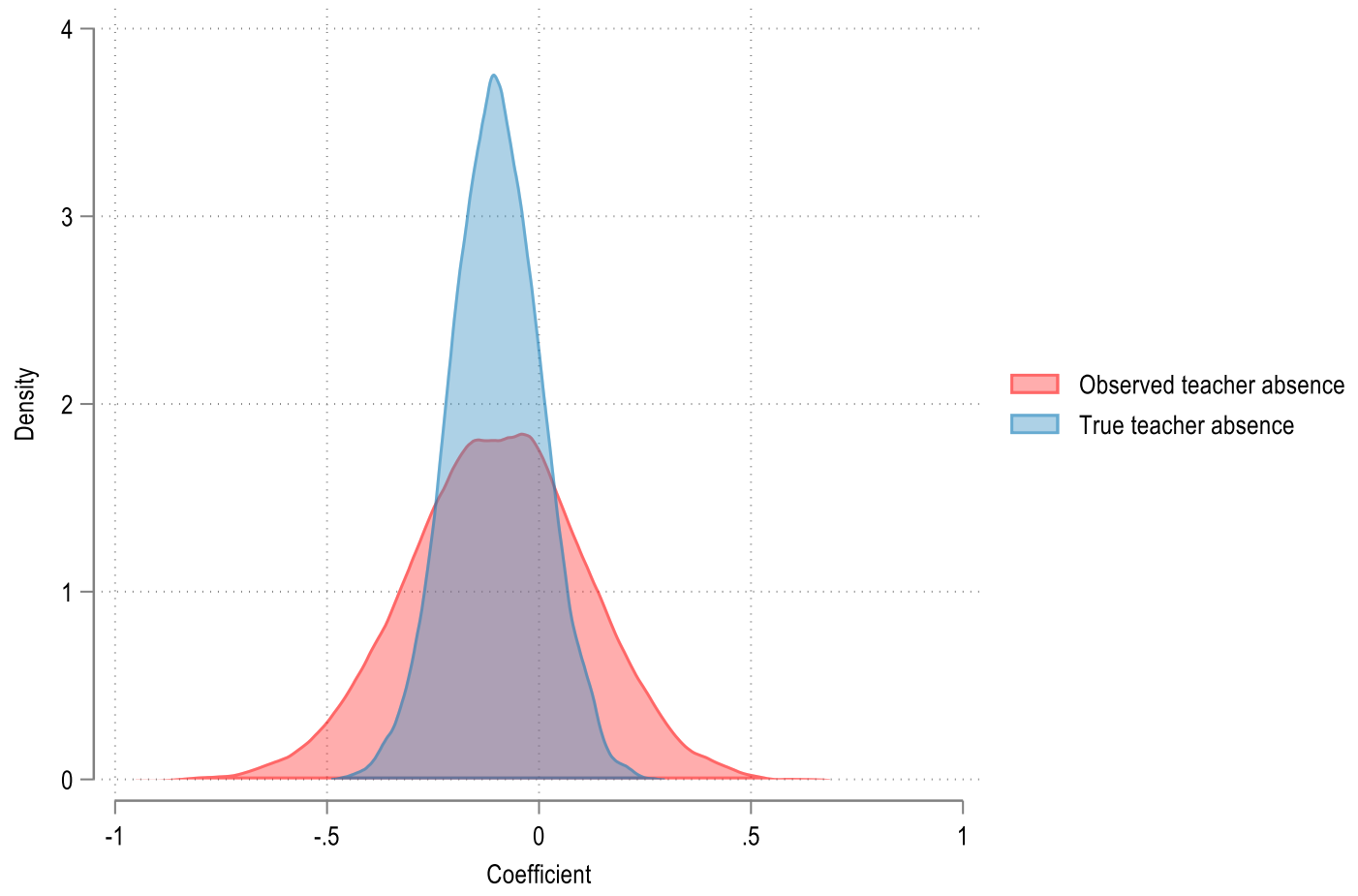

Appendix Figure C1: Distribution of the coefficients across the 10,000 draws. 


\section{Stata syntax to replicate Appendix Table C1 and Appendix Figure C1}

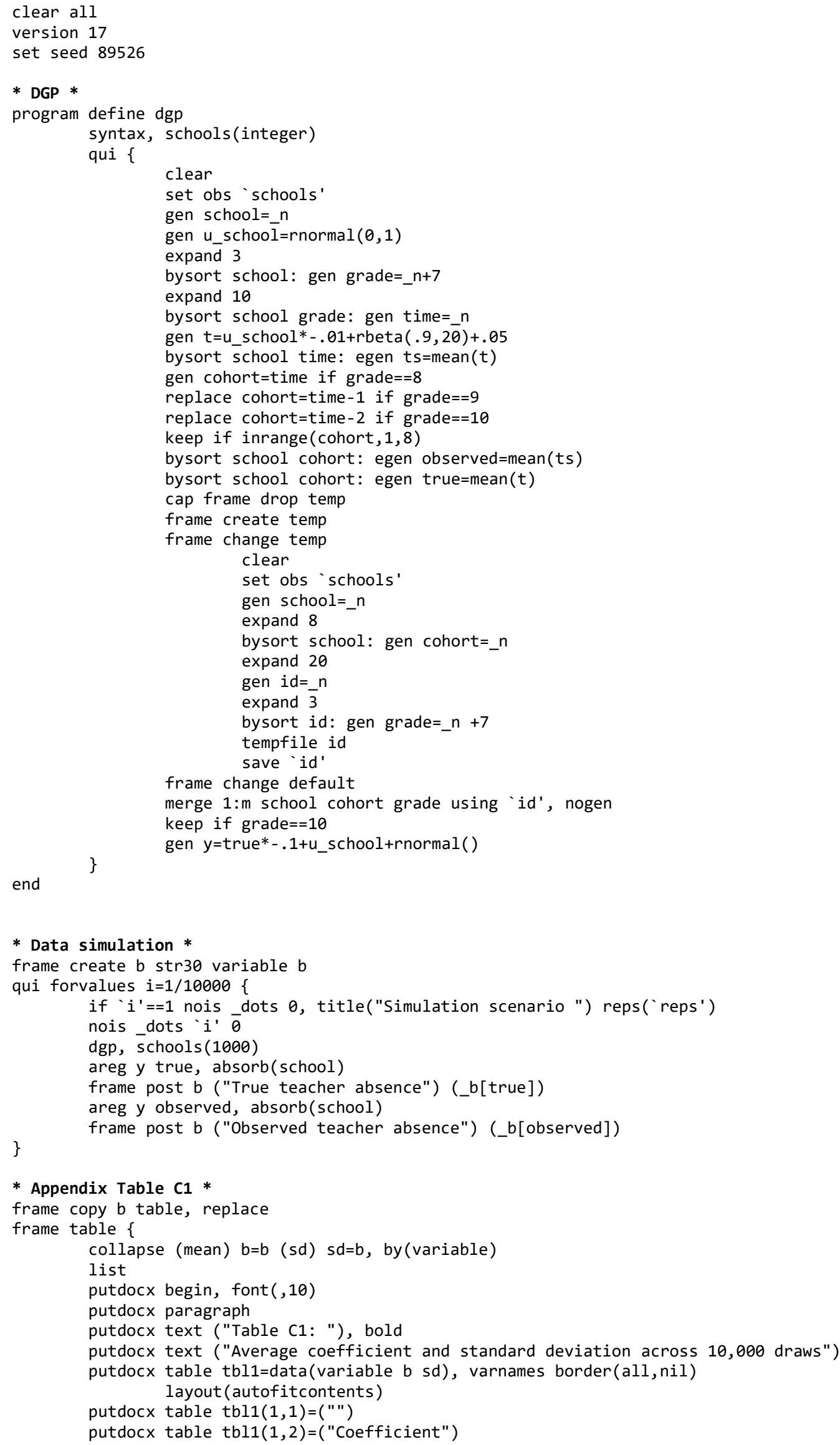




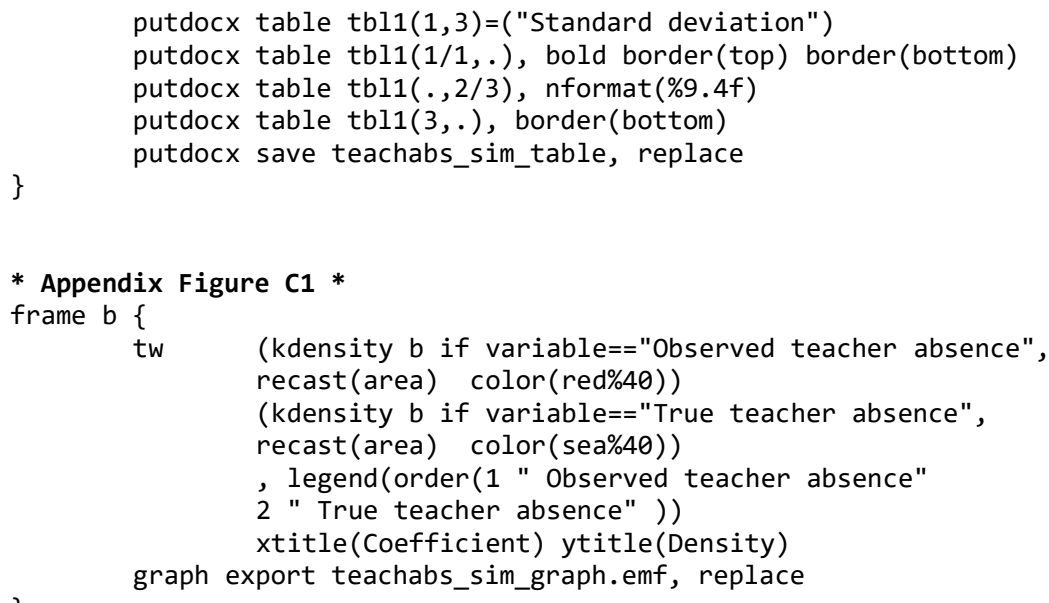

* Appendix Figure C1 *

frame $b\{$

tw (kdensity $b$ if variable=="Observed teacher absence", recast(area) color (red\%40))

(kdensity b if variable=="True teacher absence",

2 " True teacher absence" ))

xtitle(Coefficient) ytitle(Density)

graph export teachabs_sim_graph.emf, replace 